\title{
Priming sentence planning
}

\section{Agnieszka E. Konopka*, Antje S. Meyer}

Max Planck Institute for Psycholinguistics, Radboud Universiteit Nijmegen, The Netherlands

\section{A R T I C L E I N F O}

\section{Article history:}

Accepted 8 April 2014

\section{Keywords:}

Incrementality

Message and sentence formulation

Lexical priming

Structural priming

\begin{abstract}
A B S T R A C T
Sentence production requires mapping preverbal messages onto linguistic structures. Because sentences are normally built incrementally, the information encoded in a sentence-initial increment is critical for explaining how the mapping process starts and for predicting its timecourse. Two experiments tested whether and when speakers prioritize encoding of different types of information at the outset of formulation by comparing production of descriptions of transitive events (e.g., A dog is chasing the mailman) that differed on two dimensions: the ease of naming individual characters and the ease of apprehending the event gist (i.e., encoding the relational structure of the event). To additionally manipulate ease of encoding, speakers described the target events after receiving lexical primes (facilitating naming; Experiment 1) or structural primes (facilitating generation of a linguistic structure; Experiment 2). Both properties of the pictured events and both types of primes influenced the form of target descriptions and the timecourse of formulation: character-specific variables increased the probability of speakers encoding one character with priority at the outset of formulation, while the ease of encoding event gist and of generating a syntactic structure increased the likelihood of early encoding of information about both characters. The results show that formulation is flexible and highlight some of the conditions under which speakers might employ different planning strategies.
\end{abstract}

(c) 2014 Elsevier Inc. All rights reserved.

\footnotetext{
* Corresponding author. Address: Max Planck Institute for Psycholinguistics, PO Box 310, 6500 AH Nijmegen, The Netherlands.

E-mail address: agnieszka.konopka@mpi.nl (A.E. Konopka).
} 


\section{Introduction}

To produce language, speakers must decide what they want to say and how they want to say it that is, they must formulate a preverbal message and a corresponding utterance. At the sentence level, the formulation process involves several steps. For example, when asked to describe a picture of a dog chasing a mailman, speakers must select referential terms from a range of potentially suitable nouns (e.g., man or mailman to refer to the patient in this event) and must select one out of a range of suitable syntactic structures (e.g., active, passive, or intransitive constructions). Numerous production studies have shown that the availability of lexical and structural information can influence selection processes as well as production speed (e.g., Bock, 1986a, 1986b; Smith \& Wheeldon, 2001). Questions about the relative contributions of words and structures to grammatical encoding have inspired a number of hypotheses about interactions between these processes (Bock, 1982; Bock \& Griffin, 2000; Hartsuiker, Bernolet, Schoonbaert, Speybroeck, \& Vanderelst, 2008; Pickering \& Branigan, 1998) and have led to the development of detailed production models (e.g., Chang, Dell, \& Bock, 2006; Kempen \& Hoenkamp, 1987).

Differences between models reflect different assumptions about the division of labor between lexical and structural processes in the shaping of sentence form (Bock, 1987a). On the one hand, lexicalist accounts propose that structure building has a lexical source (e.g., Bates \& MacWhinney, 1982): retrieving a word provides access to structural information stored with this word at the lemma level and thus triggers the assembly of a syntactic structure. On the other hand, abstract structural accounts posit that structures can also be built by lexically-independent structural procedures (Bock, 1986a): when preparing their utterances, speakers may first generate an abstract structural framework and then retrieve the necessary words in the order required by these structures. Experimental work testing these accounts is found in the production (Bock, 1986a, 1986b, and others) as well as acquisition (Fisher, 2002; Tomasello, 2000) literature.

Here we take the position that debates about the relative timing of lexical and structural encoding are also important for explaining how speakers formulate and map preverbal messages onto language. Namely, production processes can be divided into two large classes, one concerned with encoding of individual elements of a message (non-relational processes) and the other concerned with encoding the relationships between them (relational processes). The distinction applies both to sentence-level and message-level encoding. At the sentence level, non-relational and relational information is carried by words and structures respectively; at the message level, these processes refer to identification of characters participating in an event (a dog, a mailman) and to encoding of the who-did-what-to-whom, relational structure of the event (one character chasing the other character). Since some combination of non-relational and relational processing at the message level and at the sentence level is necessary to produce any utterance longer than one word, the coordination of these processes is important for explaining information flow in the production system from conceptualization to linearization.

A crucial part of this puzzle is the fact that message-level and sentence-level processes are normally interleaved during production. All psycholinguistic models agree that messages and sentences are built incrementally, i.e., that speakers plan what they want to say in small chunks rather than in sentence-sized units (Levelt, 1989; see Wheeldon, 2013, for a review). The high degree of temporal overlap in message-level and sentence-level encoding requires a theory about dependencies between conceptual and linguistic processes. Notably, the two leading accounts of incrementality in sentence production take different views on the way that speakers generate message-level and sentence-level increments. One proposal (linear incrementality; Gleitman, January, Nappa, \& Trueswell, 2007) assumes that speakers can prepare a sequence of small conceptual and linguistic increments without guidance from a higher-level framework. The other proposal (hierarchical incrementality; Bock, Irwin, \& Davidson, 2004; Bock, Irwin, Davidson, \& Levelt, 2003) assumes that formulation can instead begin with encoding of the gist of an event and with generation of a conceptual framework to guide subsequent linguistic encoding. The difference between these proposals lies in different assumptions about the way that non-relational and relational information are combined during early formulation, much the same way that production models differ in the extent to which they give either words or structures priority during grammatical encoding. 
Addressing this debate, the two experiments reported in this paper tested whether the production system supports flexibility in message and sentence formulation, allowing speakers to prioritize encoding of either non-relational or relational information in different contexts. We first describe the key assumptions of each account of incremental sentence formulation. Then, we examine whether changes in the ease of encoding lexical and structural information favor one form of incrementality over another during production of sentences like The dog is chasing the mailman. In Section 4, we outline how and why speakers may flexibly shift between different planning strategies.

\subsection{Incrementality in message and sentence formulation}

Incrementality is often described as an adaptive property of the production system (Ferreira \& Swets, 2002; Konopka, 2012; Levelt, 1989; Wagner, Jescheniak, \& Schriefers, 2010): by allowing speakers to prepare a sequence of small units, incrementality distributes the cognitive burdens of planning over a series of words and thus lightens the load on the processor throughout the formulation process. For theoretical and practical reasons, most accounts of incrementality focus on encoding of the first increment of a message and sentence - i.e., on the selection of a starting point that initiates the mapping of a preverbal message onto language (Bock et al., 2003, 2004). Experimental evidence for these accounts comes largely from eye-tracking studies where speakers are asked to describe pictures on a computer screen: the pattern of speakers' eye movements directed to different parts of the display reveals what they encode with priority at various points in time when preparing their utterances, providing insight into the online formulation of preverbal messages and their corresponding linguistic descriptions (e.g., Brown-Schmidt \& Tanenhaus, 2006; Griffin, 2004; Griffin \& Bock, 2000; Meyer \& Lethaus, 2004).

In the case of sentences describing coherent pictured events (e.g., a dog chasing a mailman), starting points may be selected on the basis of different types of information. One way of selecting a starting point is to quickly identify a salient character and encode it as the first character of the sentence (i.e., the grammatical subject in English). The strongest support for this proposal comes from studies showing that the perceptual salience of a character is sufficient to anchor this character as a starting point. For example, Gleitman et al. (2007) presented subliminal cues in the location of a character in an upcoming pictured event and showed increased production of descriptions with the cued character in subject position. Importantly, the cues directed speakers' gaze to this character within $200 \mathrm{~ms}$ of picture onset and speakers continued fixating this character preferentially until speech onset (approximately $2 \mathrm{~s}$ later).

This pattern of eye movements supports two conclusions: it suggests that the timing of visual uptake of information in a scene can control the order of encoding operations (the character that is fixated first is also encoded first) and that the first-fixated character can be assigned to subject position without extensive encoding of the second character. As a result, the first increment of the message and sentence may consist only of information specific to one character (non-relational information) and not of information about its role in the event (relational information). The rest of the message and sentence is then built to accommodate production of the cued character in subject position: speakers shift their attention and gaze to the second character only around speech onset and begin adding it to their message and sentence as the sentence object. This planning strategy is referred to as linear incrementality as it assumes that there is a simple, one-to-one mapping between vision and language: messages and sentences can be encoded, roughly, concept by concept and word by word (also see Osgood \& Bock, 1977; Tomlin, 1995, 1997), and the relational structure of the event emerges from the series of binding operations performed with the addition of each new concept and new word to the sentence.

On a competing, hierarchically incremental account, the mapping of visual information onto language is mediated by formulation of a complex, higher-level message "plan." Hierarchical incrementality predicts that relational processing initiates, rather than follows, the encoding of any one increment (Bock et al., 2003, 2004; Kuchinsky \& Bock, 2010; Kuchinsky, Bock, \& Irwin, 2011). Griffin and Bock (2000) provide support for this view by showing that, when characters in an event do not differ in perceptual salience, speakers have no clear preference for either character in the first $400 \mathrm{~ms}$ of picture inspection. Convergence of fixations to the two characters in this time window is 
interpreted as indicating a period of event apprehension where speakers encode the gist of the event rather than favoring encoding of a single character (cf. Gleitman et al., 2007). In transitive events (e.g., a dog chasing a mailman), apprehension involves the generation of a rudimentary message framework that captures the who-did-what-to-whom causal structure of the event (one character chasing another) and that identifies the two characters by the roles they play in the event (the chaser and the chasee). This framework provides a form of top-down guidance at the outset of formulation: it allows speakers to select a starting point based on their construal of what the event is "about" and on their choice to take either character's perspective instead of automatically assigning a salient character to subject position without encoding its role in the event (analogous effects are found in the visual search literature where cognitive relevance appears to quickly take precedence over perceptual salience in controlling visual search patterns; see e.g., Henderson, Malcolm, \& Schandl, 2009). The message framework also provides a blueprint for subsequent linguistic encoding: it controls deployment of gaze at approximately $400 \mathrm{~ms}$ to the character selected to be the sentence subject and then, around speech onset, to the character selected to be the sentence object.

By defining the roles of the event characters on the basis of relational information shortly after picture onset, hierarchical incrementality implies that early planning must be fairly extensive: increments of the sentence generated before speech onset (e.g., The dog ... in an active sentence) must be larger than later increments (... the mailman) as they include conceptual information about the event as a whole and then linguistic information about the subject character. By comparison, planning of the second increment (the object character) is relatively fast: having already encoded this character's role in the event during the apprehension period, speakers must only complete linguistic encoding of its name to add it to the sentence once they have finished encoding the first character. A similar formulation process has been shown to support production of much simpler and overlearned utterances like time expressions (e.g., eight twenty; Bock et al., 2003; Kuchinsky et al., 2011), where preparation times for the first element of the utterance (eight...) are longer that for the second element (...twenty).

In short, the two leading accounts of incrementality emphasize different criteria for the selection of starting points and make different assumptions about when and how speakers encode non-relational and relational information within one utterance. Differences between these accounts are remarkable because they touch on fundamental questions about the way speakers formulate "thoughts" and the way that this information undergoes linearization: reliance on either non-relational or relational processes to initiate formulation has implications for the size and content of the first increment as well as for planning of all subsequent increments (see Bock et al., 2004, for a review of a discussion that dates back to Wundt and Paul). At the same time, both accounts are intuitively appealing as speakers can plausibly employ either planning strategy to produce well-formed sentences: on the one hand, speakers can build sentences to talk about things that capture their attention in a bottom-up fashion (Gleitman et al., 2007) and, on the other hand, they can build sentences to express ideas that are organized around some propositional content (Bock et al., 2004).

We outline a proposal for finding a middle ground in this debate: a continuum of incrementality with flexible selection of either planning strategy. Our approach largely follows from two recent findings in the literature on incrementality and planning scope. First, different messages may lend themselves to different types of planning strategies. Kuchinsky and Bock (2010) noted that the results outlined above in support of linear and hierarchical incrementality were obtained in studies employing pictures of events that differed in the ease of apprehension (i.e., the ease of relational encoding or the ease of encoding event gist): unambiguous events in Griffin and Bock (2000) and substantially more difficult events in Gleitman et al. (2007). The unambiguous events elicited similar descriptions across speakers, suggesting high consensus in speakers' interpretation of the events and thus of the underlying message representations, while the ambiguous events elicited a wider range of descriptions, suggesting large differences in the content of speakers' messages. Kuchinsky and Bock (2010) hypothesized that the harder it is to understand the gist of an event, the more likely speakers might be to use a linearly incremental strategy. They tested this hypothesis using a subliminal cuing paradigm similar to Gleitman et al. (2007): speakers described pictures of "easy" and "hard" events in which one of the characters had been cued before picture onset. Ease of conceptualization was confirmed with a codability measure that takes into account the number of different verbs used to 
describe a depicted action (Shannon's entropy): events that are consistently described with a small set of verbs are considered to be more codable, and thus permit faster encoding of event gist, than events described with a wider range of verbs. Indeed, the perceptual salience of individual characters in Kuchinsky and Bock's (2010) study did not uniformly predict their assignment to subject position: the effect of cuing on selection of starting points was weaker in higher-codability than lower-codability events. This suggests that speakers did not rely on the salience of individual characters to select a starting point when they found it easy to do so on conceptual grounds. The results thus indicate a departure from linearly incremental planning (as advocated by Gleitman et al., 2007) when relational encoding is facilitated by the nature of the message (also see Myachykov, Garrod, \& Scheepers, 2012, for an integrative approach to comparing linguistic and non-linguistic determinants of structure choice).

Second, variability in planning scope can also result from a range of processing constraints. For example, differences in planning scope are often observed across studies eliciting sentences with simpler conceptual structures (e.g., The axe and the cup... or The axe is next to the cup). Relationships between objects in such sentences are arbitrary, which should generally favor linear (i.e., sequential) encoding. However, planning scope has been shown to range from one to two objects (see Konopka, 2012, for a review). This variability can be attributed to several factors: it may reflect different goals that speakers have as they prepare their utterances (speed vs. fluency; e.g., Ferreira \& Swets, 2002) and it may follow from language-specific and language-general processing bottlenecks. For example, the order of encoding operations can be influenced by the phrasal syntax of a language (BrownSchmidt \& Konopka, 2008) and parallel processing can depend on the availability of processing resources (Konopka, 2012; Wagner et al., 2010).

When applied to production of sentences with more complex conceptual structures (like transitive sentences), these results imply that the timecourse of sentence formulation may vary systematically between as well as within messages. Production may thus be neither strictly linearly incremental nor strictly hierarchically incremental. Instead, if the way that speakers assemble different pieces of information to produce full sentences can be controlled by a number of factors, the formulation process may resemble linear, word-by-word planning and hierarchical, conceptually-driven planning in different contexts. More generally, the strong versions of linear and hierarchical incrementality may be better viewed as opposite ends of one continuum rather than representing two discrete planning strategies.

What determines whether formulation of any one message and sentence falls towards one end or the other end of this continuum? The hypothesis evaluated in this paper is that reliance on these planning strategies should depend on the ease of non-relational and relational encoding, as well as on interactions between these processes. Linear incrementality defines increments in terms of nonrelational, character-specific information, whereas hierarchical incrementality gives precedence to relational over non-relational encoding. Thus if increments generated by applying a linearly incremental or a hierarchically incremental planning strategy are encoded by prioritizing different types of information, then differences in sentence formulation should be observed under two conditions. First, the timecourse of formulation should vary systematically across events with different non-relational and relational properties (such as the ease of encoding individual characters and the ease of encoding event gist). Second, formulation should shift from one end of the continuum to the other end of the continuum whenever processes responsible for encoding non-relational and relational information become easier or harder to execute.

We report the results of two eye-tracking experiments that examined differences in the timecourse of formulation for descriptions of transitive events. In both experiments, participants saw and described a list of pictures while their gaze and speech were recorded. The agent and patient characters in the target events ( $n=30$ in each experiment) varied in ease of naming (character codability) and performed actions that were easier or harder to describe (event codability; Kuchinsky \& Bock, 2010). In addition, the ease of retrieving character names was manipulated in Experiment 1 via lexical priming, and the ease of generating active and passive structures was manipulated in Experiment 2 via structural priming. Of these four variables, two provided a measure of the ease of non-relational encoding (character codability and ease of lexical retrieval) and two were more closely tied to relational encoding (event codability and the ease of assembling syntactic structures). Within each variable type, one 
reflected item-specific properties and one was experimentally manipulated. Together, these variables capture variability in encoding that can arise at the message level as well as the sentence level. Earlier work showed that all four variables can influence sentence form (Bock, 1986a, 1986b; Kuchinsky \& Bock, 2010), and detailed predictions with regard to the timecourse of formulation are listed below (Sections 1.2 and 1.3).

\subsection{Encoding characters and actions}

Message-level properties of events that bear on the formulation process are the identities of individual characters (non-relational information) and their relationship to one another (relational information). The pictured events used in Experiments 1 and 2 varied on both dimensions. Using Kuchinsky and Bock's (2010) approach, estimates of the ease of encoding characters and actions were based on the heterogeneity of speakers' descriptions.

Variability in event descriptions is expected in open-ended production tasks because different speakers can interpret the same event in different ways. For example, speakers can choose to emphasize different aspects of a character's identity (e.g., man vs. policeman) or take different perspectives on the same action (e.g., kicking vs. pushing). For character naming, the index of conceptual difficulty is thus heterogeneity in speakers' noun choice: characters referred to consistently with a small set of nouns are assumed to be more codable than characters with lower name agreement. For actions, the index of conceptual difficulty is heterogeneity in verb choice: events that are consistently described with a small set of verbs are assumed to be more codable than events eliciting a wider range of verbs. ${ }^{1}$

We first examined whether character codability and event codability influenced what speakers said and then whether they influenced how speakers assembled their sentences. If formulation is flexible, then variations in character codability and event codability across items should shift control of formulation from a relational to a non-relational source, and vice versa. Effects of these variables may be observed at two points in the formulation process: first, during selection of a starting point and encoding of the first character (Gleitman et al., 2007, vs. Kuchinsky \& Bock, 2010), and, second, during the addition of the second character to the sentence. Since the two experiments used a highly overlapping set of target items, the same predictions apply to both experiments.

First, variations in character codability should produce accessibility effects in sentence form and in early gaze patterns to target characters. Speakers have a strong preference to begin sentences with accessible characters (Altmann \& Kemper, 2006; Bock, 1987b; Bock \& Irwin, 1980; Bock \& Warren, 1985; Branigan, Pickering, \& Tanaka, 2008; Christianson \& Ferreira, 2005; Ferreira, 1994; McDonald, Bock, \& Kelly, 1993; Prat-Sala \& Branigan, 2000), so easy-to-name characters should become subjects more often than harder-to-name characters. These effects are generally compatible with a strong, linearly incremental account of planning where starting points are selected based on the ease of encoding non-relational information. Consequently, we expected character codability to also predict assignment of first-fixated characters to subject position: first-fixated characters should become subjects more often when they are easy to name than when they are harder to name, demonstrating a direct link between character accessibility and selection of starting points. The strong version of linear incrementality also predicts that this selection process should occur during the earliest stages of formulation: fixations to the two characters should diverge quickly after picture onset (within $200 \mathrm{~ms}$ of picture onset; Gleitman et al., 2007) when an "easy" character in produced in subject position and speakers should continue fixating the subject character preferentially until speech onset.

\footnotetext{
${ }^{1}$ In principle, heterogeneity in noun and verb choice can arise both during message-level encoding as well as during lexicalization (sentence-level encoding). For example, after identifying a character, speakers may need to select one noun from a range of synonymous nouns to express this information linguistically. Similarly, having apprehended what action two characters are performing, speakers may need to select one verb from a range of nearly synonymous verbs. Fine-grained semantic differences between nouns and verbs that different speakers use in their descriptions may thus reflect either fine-grained differences in interpretation, fine-grained differences in the accessibility of individual nouns and verbs, or both. For present purposes, character codability and event codability are used as an umbrella measure of how easily speakers identify individual characters (nonrelational information) and express what an event is "about" (relational information), regardless of the locus or origin of differences in word choice.
} 
In contrast, the effect of event codability on early formulation should be to reduce the impact of first fixations and character codability on selection of starting points. Replicating Kuchinsky and Bock (2010), speakers should begin their sentences with first-fixated characters or easy-to-name characters less often in higher-codability than lower-codability events. Early eye movements should also show sensitivity to higher-level event properties (see Bock et al., 2003; Dobel, Gumnior, Bolte, \& Zwitserlood, 2007; Hafri, Papafragou, \& Trueswell, 2012, for demonstrations of rapid encoding of event gist). Speakers should be less likely to prioritize encoding of one character over the other character in the first $400 \mathrm{~ms}$ of picture inspection in higher-codability events than in lower-codability events; instead, they should direct their gaze preferentially to the subject character later in higher-codability events, resulting in slower divergence of fixations to the two characters in higher- than lower-codability events immediately after picture onset. In other words, formulation should begin with a period where speakers distribute their attention roughly evenly between the two characters when the gist of an event is easy to encode, as predicted by the strong version of hierarchical incrementality (Bock et al., 2003, 2004; Griffin \& Bock, 2000).

Second, we extend the predictions of linear and hierarchical incrementality to processes required to add the second character to the developing sentence. We propose that differences in planning strategies across events may also be observable in the timing of gaze shifts from the first character to the second character around speech onset. The duration of gazes to a character immediately before production of its name is assumed to index the speed of lexical retrieval (name-related gazes; Griffin, 2004; Meyer \& Lethaus, 2004), so, in all events, speakers were expected to fixate easyto-name (high-codability) subject characters for less time than harder-to-name (lower-codability) subject characters. However, the extent to which speakers encoded relational information about the event (i.e., information about both the first and second character) at the outset of formulation should also influence the length of gazes to the subject character. Linear incrementality predicts that early planning does not extend beyond the first character, so this planning strategy should confer no benefits for encoding of the second character mid-way through the sentence: the timing of gaze shifts away from the first character and towards the second character should depend on character codability but should not differ between higher-codability and lower-codability events. In contrast, hierarchical incrementality assumes early encoding of relational information after picture onset and thus allows for top-down control of linguistic encoding: the second character should be easier to add to the developing sentence when formulation is supported by a conceptual framework, so speakers may initate gaze shifts to the second character earlier in higher-codability than lowercodability events.

Finally, if changes in formulation are observed across events differing in codability of characters and actions, interactions between character codability and event codability should highlight the relative sensitivity of the production system to non-relational and relational variables. On the one hand, if the production system generally favors linearly incremental planning, the ease of encoding nonrelational information should control the extent to which relational properties of an event also influence formulation: character codability should be the strongest predictor of formulation, allowing effects of event codability to be observable relatively late in the formulation process or only when characters are difficult to encode (i.e., in events where speakers may need to fall back on other types of information to formulate their sentences). On the other hand, if the production system generally favors hierarchically incremental planning, event codability should control the extent to which properties of agents and patients also influence formulation: character codability should play a weak role in formulation for high-codability events and a stronger role for low-codability events (i.e., events where speakers may need to fall back on non-relational information to formulate their sentences).

\subsection{Retrieving words and assembling structures}

Message-level planning involves encoding of non-relational and relational information, so the mapping of conceptual representations onto language also takes place via processes responsible for encoding two types of information. Production models agree that the mapping from concepts to language occurs via the process of lemma selection (for content words) and function assignment (for links between concepts, thematic roles, and structure-building procedures). In this sense, words 
and structures carry non-relational and relational information respectively: nouns (like dog and mailman) describe referents, rather than the relationship between referents, whereas structures (like actives and passives) express these relationships, irrespective of the identity of the referents. ${ }^{2}$

Since speakers are able to pass on conceptual information to linguistic encoding as soon as it becomes available, both lexical and structural processes can be expected to systematically influence the timecourse of formulation. Importantly, lexical and structural processes have different implications for incrementality because words and structures have an inherently different scope (Konopka, 2012): retrieving a character name does not require planning of material beyond this character, whereas generation of a structure inherently involves preparation of information that extends beyond a single character. Thus prioritizing lexical encoding is generally compatible with the main tenets of linear incrementality, and prioritizing encoding of structural information is more compatible with hierarchical incrementality.

As outlined earlier, discussions about the role of words and structures in formulation bear a strong similarity to questions about lexical-structural integration - i.e., the long-standing debate about lexical and structural guidance in grammatical encoding (Bock, 1987a; see Pickering \& Ferreira, 2008, for a review). Sentence form is a product of both lexical and structural constraints, but lexicalist and abstract structural accounts assume that speakers prioritize encoding of either words or structures: in a lexical system, words trigger structural assembly (lexical guidance), and in an abstract structural system, structures can be generated without lexical support (structural guidance). The types of dependencies between words and structures described by these accounts have the same implications for formulation as linear and hierarchical incrementality: lexical guidance assumes that non-relational processes take precedence over relational processes, while structural guidance gives abstract structures a more prominent role in shaping sentence form.

One approach to testing for effects of lexical and structural guidance on formulation is to experimentally vary the ease of lexical and structural encoding. In the current experiments, we manipulate these processes via lexical and structural priming. Lexical priming involves presenting speakers with words that are semantically or associatively related to a referent in the target picture (e.g., pony or milk before a picture of a horse kicking a cow; Bock, 1986b). Processing of the prime words increases the activation and hence the accessibility of target words, and thus increases production of sentences with primed, easy-to-name characters in subject position. Similarly, structural priming involves exposing speakers to syntactic structures that may be used to describe target events, and thus increases the likelihood of speakers using the primed structure on the target trial (Bock, 1986a).

Experiment 1 used lexical primes embedded in intransitive sentences to increase the accessibility of the agent and patient characters in target events, and Experiment 2 used structural primes to facilitate assembly of a transitive structural frame. The paradigms were adapted from Bock (1986a, 1986b): on prime trials, speakers saw pictured events and heard recorded descriptions, while on target trials, they were asked to describe new pictures themselves. Speakers were expected to produce more active sentences after agent-related primes than patient-related primes (Experiment 1) and more active sentences after active primes than passive primes (Experiment 2). Importantly, if formulation is flexible, then any changes in structure choice resulting from lexical and structural priming should also be accompanied by changes in the timecourse of formulation.

Specifically, facilitating encoding of individual characters in Experiment 1 should result in an early accessibility effect: a first-fixated character should be produced in subject position more often if it had been primed than if it had not been primed, and speakers should spend more time fixating primed subject characters than unprimed subject characters immediately after picture onset $(0-400 \mathrm{~ms})$. Both results would indicate priority encoding of accessible characters before less accessible characters. This is analogous to the predicted effect of character codability on early formulation (Section 1.2), and

\footnotetext{
${ }^{2}$ This discussion of content words is limited to nouns for maximum contrast between linguistic elements that express nonrelational and relational information. Naturally, relationships between referents are also expressed lexically with content words like verbs. Verb choice can provide an indication of speakers' interpretation of the conceptual structure of the event, and indeed, the measure of event codability used to assess the ease of relational encoding is based on verb heterogeneity. Thus for present purposes, verbs can be viewed as being more similar to structures in terms of their relational content than nouns (see Fisher, Gleitman, \& Gleitman, 1991, for a detailed discussion of the semantics of different verb classes).
} 
indicates a shift towards linearly incremental planning. In contrast, facilitating encoding of sentence structure in Experiment 2 should reduce the likelihood of speakers fixating one character preferentially over the other character immediately after picture onset: speakers should be more likely to distribute their attention between two characters when producing a primed structure than an unprimed structure. This is similar to the predicted effect of event codability on formulation (Section 1.2) and illustrates a shift towards hierarchical incrementality.

Later in the formulation process (i.e., between $400 \mathrm{~ms}$ and speech onset), the lexical and structural primes should both also influence the timing of gaze shifts from the first to the second character: lexical primes should reduce the length of gazes on a primed subject character by facilitating encoding of its name and structural primes should reduce the length of gazes on the subject character by facilitating encoding of the entire event. Importantly, despite similar outcomes, the reasons for these effects can be traced back to qualitative differences in planning strategies in the two experiments.

\subsection{Overview of experiments}

In sum, in two experiments, we undertook a systematic analysis of the influence of non-relational and relational variables on the timecourse of formulation for simple event descriptions. Similar results were expected for the two variables influencing the ease of non-relational processing (character codability and lexical accessibility) and the two variables influencing the ease of relational processing (event codability and ease of generating linguistic structures).

Analyses in each experiment first verified whether all variables had the expected effect on speakers' descriptions of target events (i.e., structure choice). First, character codability was expected to influence the assignment of characters to subject or object position based on their relative ease of naming in both experiments, and lexical priming was expected to produce a similar effect in Experiment 1 . Second, structure choice was evaluated with respect to event codability and structural priming. Event codability was not expected to influence structure selection on its own as the difference between an active frame and a passive frame is not inherently linked to the ease of encoding event gist, but the structural primes in Experiment 2 were expected to produce the well-documented structural priming effect.

After confirming effects of these variables on structure selection, we examined whether and how they also shaped the timecourse of formulation in active sentences (i.e., descriptions of events with the preferred active structure; see Van de Velde, Meyer, \& Konopka, 2014, for discussion of formulation of sentences with the dispreferred passive structure). We began by testing whether first fixations predicted sentence form across items and conditions. Timecourse analyses were then carried out to compare the distribution of fixations to the two characters over time in early (0-400 ms) and late (400 ms - speech onset) time windows across items and conditions. To summarize the predictions, character codability and lexical priming were expected to (a) favor selection of the first-fixated character as the starting point and (b) favor priority encoding of this character after picture onset (the strong version of linear incrementality). In contrast, event codability and structural priming were expected to (a) reduce the impact of first fixations on selection of starting points, (b) favor priority encoding of relational information about the event after picture onset, and (c) influence the timing of gaze shifts from the first character to the second character around speech onset (the strong version of hierarchical incrementality). We highlight effects consistent with linear and hierarchical incrementality throughout the results sections, and we refer to effects that are consistent with both accounts as supporting weaker versions of linear and hierarchical incrementality.

\section{Experiment 1}

Eye-tracked participants described a long series of pictures, including 30 target pictures of twocharacter events. They were asked to mention all characters shown in each picture, but, to approximate production in more naturalistic situations, they received no further instructions about sentence content or form. Event and character codability were estimated post hoc for each target picture. Codability ratings for events and agents in Experiments 1 and 2 were highly correlated (both $r s>.87$ ), 
showing high stability in the types of descriptions speakers produced to describe the events and warranting a direct comparison of results across experiments.

The ease of character naming in target pictures in Experiment 1 was additionally manipulated with lexical priming. Target pictures were preceded by primes where speakers saw a picture of an intransitive event and heard a recorded intransitive description. The referent shown in the prime pictures was semantically or associatively related to the agent or to the patient in the following target picture (the agent and patient prime conditions respectively) or to neither character (the neutral prime condition). The agent and patient characters were thus either primed or unprimed. The neutral condition served as a baseline to assess the overall likelihood of speakers using active and passive syntax to describe the target transitive events.

Timecourse analyses assessed differences and changes in the formulation of active descriptions for the different types of events and after the three types of primes. On the hypothesis that the ease of character naming determines the extent to which speakers prioritize encoding of a single character at the outset of formulation, speakers should be more likely to engage in linearly incremental than hierarchically incremental planning when preparing sentences that begin with an accessible character (a highly-codable character or a primed character); event codability should have the opposite effect on formulation.

\subsection{Method}

\subsubsection{Participants}

Fifty-four native speakers of Dutch (mostly university students; 48 female) from the Nijmegen area participated for payment. Four participants were replaced because they produced very few scorable responses on target trials.

\subsubsection{Materials and design}

There were four types of trials: target trials, prime trials, filler trials, and word trials. On target trials, speakers saw pictures of transitive events (see Appendix A; pictures were adapted from Bock, 1986b, and from images available in the Microsoft clipart database). There were 20 items with animate agents (13 items with human agent and 7 with animal agents), and 10 with inanimate agents. To increase production of passive sentences, 23 items had animate patients (20 items had human patients, 3 had animal patients) and 7 had inanimate patients. ${ }^{3}$

Pictures shown on prime trials were one-character events. They were accompanied by a recorded intransitive description produced by a native Dutch speaker. The characters named in these sentences were semantically related to the agent (e.g., wolf), the patient (e.g., salesman), or to neither character (e.g., umbrella) in the following target picture (in this case, a dog chasing a mailman). Semantic relatedness was verified with LSA norms (Latent Semantic Analysis; http://lsa.colorado.edu): across all events, agent primes had a stronger relationship to agents than patients $(.37$ vs. $.09 ; t(28)=6.20)$, and patient primes had a stronger relationship to patients than agents $(.23$ vs. .12; $t(29)=3.06)$. Neutral primes were not related to either character .05 and .08 for the relationship to the agent and patient respectively).

The remaining trials were unrelated to the prime and target pictures. On filler trials $(n=103)$, speakers saw pictures that could be described with a variety of structures (e.g., intransitive, dative, reflexive sentences). On 90 filler trials, speakers produced a description, and on 13 trials, they saw a picture and heard a recorded description.

Word trials were introduced to present the experiment as a memory task to participants (see Bock, 1986a, 1986b). On these trials ( $n=25$ ), participants saw a printed word appearing in the center of the screen: 15 of these words had been used previously in the experiment (e.g., they were names of characters shown in earlier pictures) and 10 were new.

\footnotetext{
${ }^{3}$ As expected, speakers produced more active sentences to describe events with animate agents than inanimate agents, and more passive sentences to describe events with animate patients than inanimate patients in both experiments. Since the effects of animacy on sentence form are well-documented in the literature, we omit discussion of animacy in this paper and focus only on character codability.
} 
The design of the experiment included one three-level factor (Prime condition: agent primes, patient primes, neutral primes). Two mirror-reversed versions of each target picture were created, one in which the agent appeared on the left hand-side and one in which the agent appeared on the right hand-side of the screen. Crossing this factor with the priming manipulation produced six different lists of stimuli, with each target picture being presented in a different Prime condition and with a different spatial layout of characters on each list. All analyses collapsed across the two mirror-reversed versions of each item. Within lists, there were 10 target pictures in each Prime condition, and no two prime-target pairs from the same condition were presented in succession. The prime-target pairs were separated by $4-5$ intervening unrelated trials (filler trials and word trials).

\subsubsection{Procedure}

Participants were seated at an Eye-link 1000 eye-tracker ( $500 \mathrm{~Hz}$ sampling rate). Instructions appeared on the screen and were paraphrased by the experimenter. Participants were told that they would see a series of pictures and of single words. Each trial began with a fixation point at the top of the screen: participants had to look at the fixation point and press a key to continue. On picture trials, they then saw a picture of an event and their task was to describe the event with one sentence, mentioning all characters shown in the event. On a subset of picture trials, participants first saw the word LISTEN printed in the center of the screen and then a pictured event accompanied by a recorded sentence: here, their task was to listen to the sentence and then repeat it out loud. On word trials, participants saw a printed word in the center of the screen instead of a picture: they were instructed to read this word out loud and decide whether they had produced it before in the experiment by saying "yes" or "no."

\subsubsection{Sentence scoring}

Sentences produced on target trials were scored as actives, full passives, or sentences with other constructions. The latter category included truncated passives, get-passives, intransitive sentences, sentences beginning with a "There is/are..." construction, and sentences with indefinite pronouns (e.g., someone). Two items were excluded from the analyses as they elicited a very small number of transitive responses and one item was excluded for technical reasons.

In the remaining dataset, trials were excluded if the first fixation in that trial was not on the fixation point at the top of the screen ( 80 trials) or if onsets were longer than $5 \mathrm{~s}$ and longer than 3 standard deviations from the grand mean ( 11 sentences). The final dataset consisted of 648 sentences (.71 actives, .29 full passives).

Sentences containing disfluencies were included in the analyses of structure choice and in timecourse analyses because disfluencies are a normal occurrence in unprepared speech. Sentences with disfluencies before the first article or first noun were, however, not included in analyses of speech onset, leaving 627 fluent sentences.

\subsubsection{Character codability and Event codability scoring}

Character codability and Event codability were estimated with Shannon's entropy based on the distribution of responses included in the analyses (see Kuchinsky, 2009). ${ }^{4}$ All the different referential terms that speakers used in their descriptions were included in the codability estimates. Higher codability scores for agents and patients indicate lower heterogeneity in speakers' choice of referential terms and thus greater ease of identification and naming. Similarly, higher codability scores for events indicate lower heterogeneity in speakers' descriptions of the action shown in the event, and thus greater ease of event apprehension and gist extraction.

\footnotetext{
${ }^{4}$ Shannon's entropy $(H)=-\sum p i \log 2(p i)$. Pi is the probability of the $i$ th word. For example, the event showing a fireman saving a boy was consistently described with the verb save (low verb heterogeneity and thus high event codability; $H=0$ ); the event showing a shark attacking a man was described with verbs like attack, bite, eat, and surprise (high verb heterogeneity and thus lower event codability; $H=1.56$ ). Similarly, the agent and patient in the event showing a horse kicking a cow were consistently described with the nouns horse and cow (high agent and patient codability; $H=0$ ); characters in the event showing a bee stinging a man were described with nouns like bee, wasp, mosquito, insect, and creature for the agent (lower agent codability; $H=2.32$ ), and nouns like man, boy, and person for the patient (lower patient codability; $H=1.13$ ).
} 
As expected, the codability scores showed large between-item differences (see Table 1 for mean scores after median splits), allowing analyses of the effects of these variables on structure choice and formulation across a range of events. Event codability scores were not correlated with Agent or Patient codability ( $r=.17$ and $-.31, n s$., respectively), so the identity of the characters had little bearing on the ease of comprehending the events. Agent and Patient codability were, however, positively correlated $(r=.42, p<.05)$ : items with easier-to-name agents contained easier-to-name patients. Patient codability scores were thus residualized on Agent codability for analyses of sentence form; since properties of the patients did not reliably predict sentence form, this factor was then dropped from all analyses. Importantly, codability ratings for agents and patients did not differ across Prime conditions (all ps > .3), showing that the lexical primes did not influence speakers' choice of referential terms for these characters and thus did not contribute further to variability in naming.

\subsubsection{Analyses}

Analyses of structure choice and speech onsets were conducted with mixed logit models and linear mixed effects models respectively in R (Baayen, Davidson, \& Bates, 2008; Jaeger, 2008). The models included a combination of Event codability, Agent codability (continuous predictions), the location of First fixations, and Prime condition (categorical predictions) as listed below. All predictors were centered. For clarity, the effects of Event and Agent codability are shown in all figures following a median split into higher- and lower-codability events ("easy" and "hard" events) with higher- and lower-codability agents ("easy" and "hard" agents). Performance in the three Prime conditions was compared with two orthogonal contrasts motivated by the data (as listed in all tables).

Analyses were carried out in four steps. The first analysis considered effects of First fixations on sentence form (Section 2.2.1), and the second analysis tested the influence of the lexical primes on sentence form (Section 2.2.2). Both analyses also tested for interactions with Event and Agent codability. The third analysis tested whether speech onsets were sensitive to differences in ease of encoding across items and conditions as well (Section 2.2.3). Finally, timecourse analyses of agent-directed fixations were carried out for with quasi-logistic regressions for active sentences (Section 2.2.4; Barr, 2008).

In all cases, to arrive at the simplest best-fitting models, full models including all interactions between factors were simplified to include only reliable interactions that improved model fit. Random slopes for fixed factors were included where mentioned only if they improved model fit (models with the full random structure often failed to converge; similar results were obtained in models with the most complex possible random structure and are therefore not reported; cf. Barr, Levy, Scheepers, \& Tily, 2013). All effects were considered to be reliable at $p<.05$, unless indicated otherwise.

\subsection{Results}

\subsubsection{First fixations and sentence form}

On the majority of scored target trials, first fixations were directed to the agent (.65). Speakers also directed more first fixations to the agent after agent primes (.66) than after neutral primes (.64) and patient primes (.64), but differences between conditions did not reach significance.

\section{Table 1}

Means (and standard deviations) of Event codability and Agent codability scores for higher- and lower-codability events with higher- and lower-codability agents in Experiments 1 and 2.

\begin{tabular}{llll}
\hline Event codability & Agent codability & Event codability score & Agent codability score \\
\hline Experiment 1 & & & $.42(.46)$ \\
High & High & $.85(.58)$ & $1.70(.59)$ \\
High & Low & $.46(.57)$ & $.33(.40)$ \\
Low & High & $1.84(.32)$ & $1.92(.45)$ \\
Low & Low & $2.11(.42)$ & \\
Experiment 2 & & & $.41(.32)$ \\
High & High & $.98(.41)$ & $2.17(.44)$ \\
High & Low & $.66(.49)$ & $.32(.28)$ \\
Low & High & $1.99(.38)$ & $2.09(.69)$ \\
Low & Low & $2.36(.51)$ & \\
\hline
\end{tabular}


More importantly, first fixations predicted selection of starting points (Fig. 1a): speakers produced .12 more actives if they looked first at the agent than if they looked first at the patient (.75 vs. .63; $\beta=.61, z=2.09$ ). Supporting linear incrementality, this result shows that selection of a starting point can be influenced by shifts of visual attention and thus by the timing of the uptake of visual information (Gleitman et al., 2007; Kuchinsky \& Bock, 2010). There were no interactions with Prime condition or with the two Codability predictors.

\subsubsection{Lexical primes, codability, and sentence form}

Lexical primes reliably influenced sentence form (Fig. 2a; Table 2): speakers produced fewer active sentences after patient primes than after other primes (agent and neutral primes; the first contrast for Prime condition in Table 2). Production of active sentences after agent primes and after neutral primes did not differ (the second contrast for Prime condition in Table 2). The asymmetry in priming effects after agent and patient primes shows that only priming of the patient character influenced speakers' selection of an active or passive structure.

Priming effects were additionally modulated by Agent codability and Event codability. Speakers produced more active sentences beginning with "easy" agents than "hard" agents (.80 vs. .60). Importantly, the lexical primes influenced sentence form only in events with "harder" agents (Fig. 2b): speakers produced fewer actives after patient primes than other primes (agent and neutral primes) to describe these events, while events with "easier" agents were less amenable to priming (resulting in an interaction between Prime condition and Agent codability; see the first contrast for

(a) Experiment 1

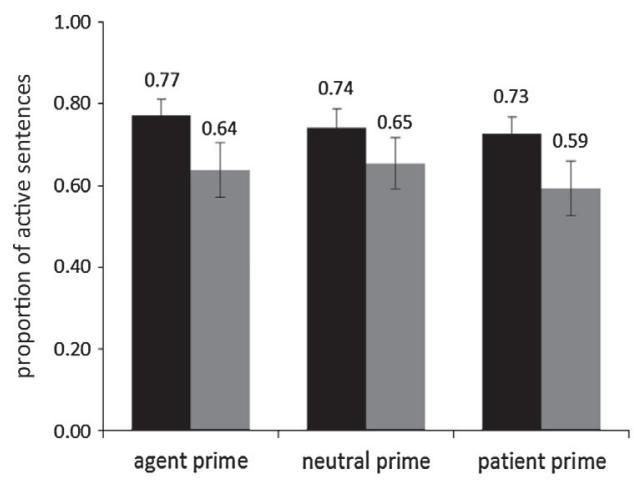

(c) Experiment 2

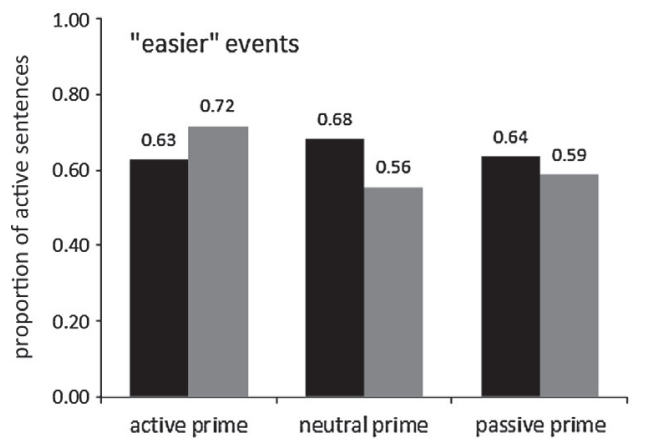

(b) Experiment 2
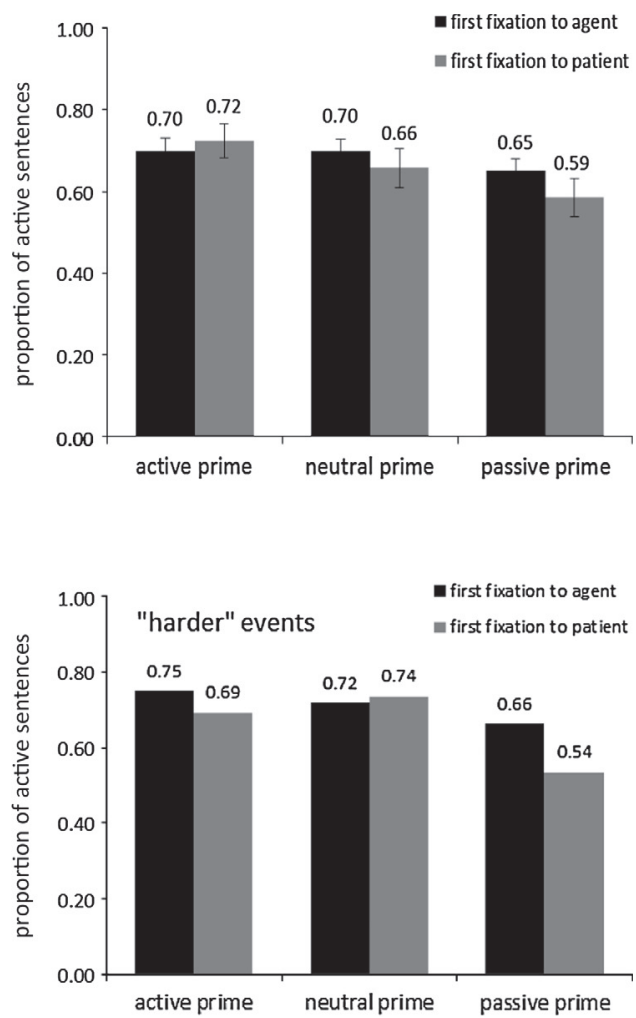

Fig. 1. Proportions of active sentences produced in (a) Experiments 1 and (b) Experiment 2 after agent-directed and patientdirected first fixations across conditions. Error bars are by-participant standard errors, (c) shows proportions of active sentences produced across condition for "easier" and "harder" events in Experiment 2. 
Experiment 1

Experiment 2

(a) all items
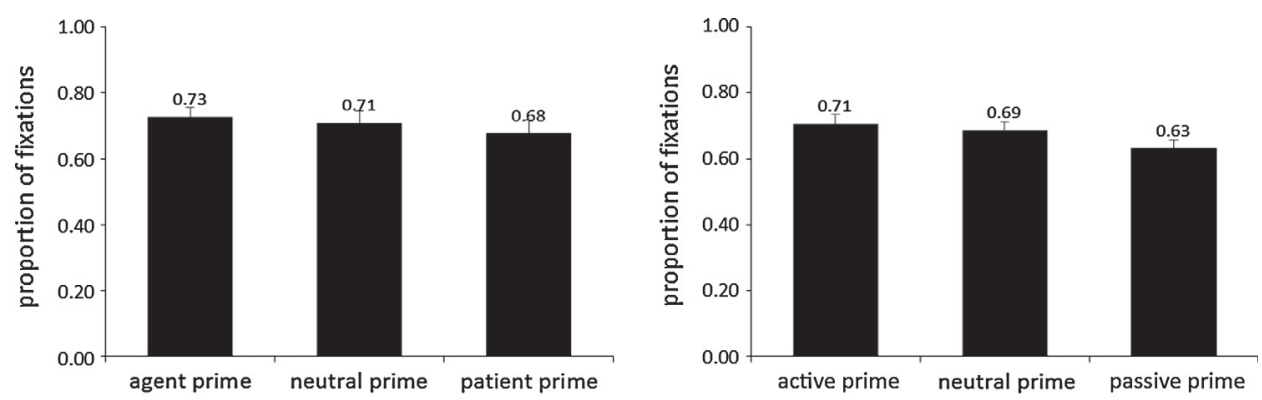

(b) agent codability
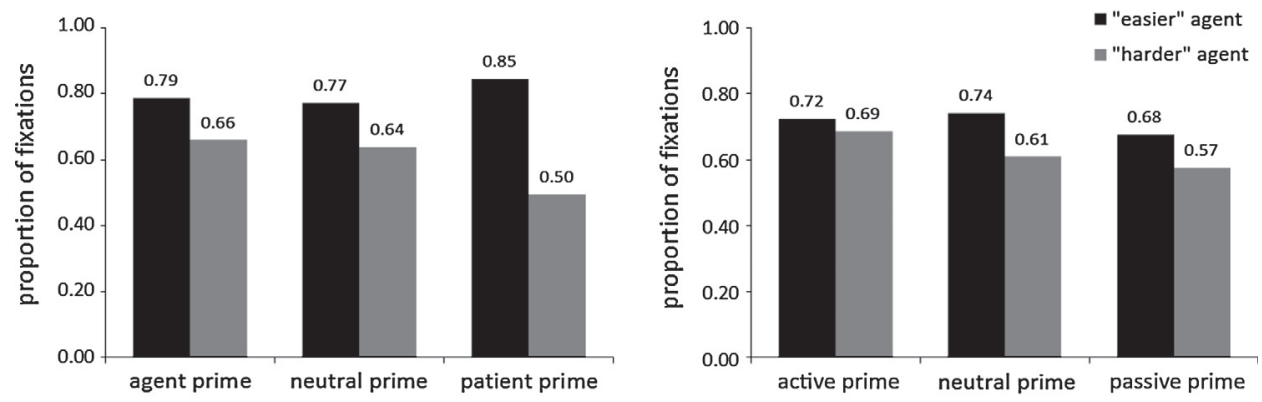

(c) event codability
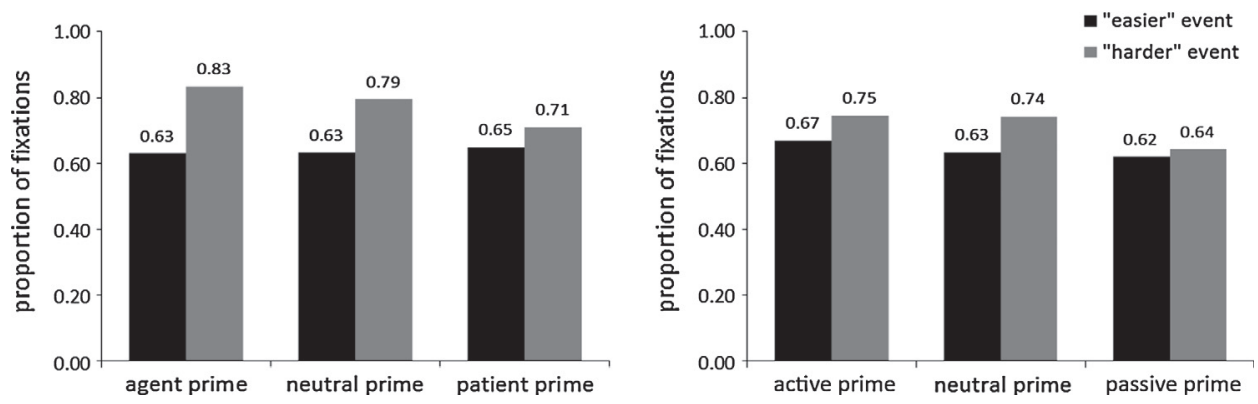

Fig. 2. Proportions of active sentences produced in Experiments 1 and 2 (a) across all items, (b) with respect to Agent codability and (c) with respect to Event codability. Error bars are by-participant standard errors.

this interaction in Table 2). Thus the lexical primes were effective primarily in cases where speakers generally preferred to postpone encoding the agent (i.e., in events with "hard" agents).

A similar effect was observed with respect to Event codability (Fig. 2c). The lexical primes influenced sentence form primarily in "harder" events: again, speakers produced fewer active sentences after patient primes than after other primes (agent and neutral primes), while descriptions of "easier" events were less more amenable to priming (resulting in an interaction between Event codability and Prime condition; see the first contrast for this interaction in Table 2). The direction of the effect is consistent with Kuchinsky and Bock's (2010) finding that perceptual cues have a stronger effect on selection of starting points in "hard" events: here, manipulating the ease of encoding patients with linguistic cues (lexical primes) instead of non-linguistic cues influenced sentence form to a greater extent in "hard" events, where starting points were difficult to select on conceptual grounds, than in "easy" events, where starting points were easier to select on conceptual grounds. 


\section{Table 2}

Production of active sentences in Experiments 1 and 2, as a function of Prime condition, Agent codability, and Event codability. (p) and (i) include addition of random by-participant and by-item slopes.

\begin{tabular}{|c|c|c|c|c|c|c|}
\hline \multirow[t]{2}{*}{ Predictor } & \multicolumn{3}{|c|}{ Experiment 1} & \multicolumn{3}{|c|}{ Experiment 2} \\
\hline & Est. & SE & $z$-Value & Est. & SE & $z$-Value \\
\hline Intercept & -1.89 & .64 & $-2.93^{*}$ & -1.24 & .38 & $-3.27^{*}$ \\
\hline $\begin{array}{l}\text { Prime condition } \\
\text { Exp. 1: patient prime vs. other primes } \\
\text { Exp. 2: passive prime vs. other primes }\end{array}$ & -.56 & .31 & $-1.80^{\dagger}$ & $-.49(\mathrm{p}, \mathrm{i})$ & .16 & $-3.09^{*}$ \\
\hline $\begin{array}{l}\text { Prime condition } \\
\text { Exp. 1: agent prime vs. neutral prime } \\
\text { Exp. 2: active prime vs. neutral prime }\end{array}$ & -.04 & .33 & -.11 & $-.07(\mathrm{p}, \mathrm{i})$ & .19 & .41 \\
\hline Agent codability & .23 & .72 & .33 & .28 & .37 & .76 \\
\hline Event codability & -.63 & .73 & -.86 & .01 & .44 & .01 \\
\hline $\begin{array}{l}\text { Prime condition } * \text { Agent codability } \\
\text { Exp. 1: patient prime vs. other primes } \\
\text { Exp. 2: passive prime vs. other primes }\end{array}$ & -1.30 & .41 & $-3.20^{*}$ & .14 & .17 & .85 \\
\hline $\begin{array}{l}\text { Prime condition } * \text { Agent codability } \\
\text { Exp. } 1 \text { : agent prime vs. neutral prime } \\
\text { Exp. } 2 \text { active prime vs. neutral prime }\end{array}$ & -.28 & .42 & -.66 & .46 & .20 & $2.30^{*}$ \\
\hline $\begin{array}{l}\text { Prime condition } * \text { Event codability } \\
\text { Exp. 1: patient prime vs. other primes } \\
\text { Exp. 2: passive prime vs. other primes }\end{array}$ & -.88 & .43 & $-2.07^{*}$ & - & - & - \\
\hline $\begin{array}{l}\text { Prime condition } * \text { Event codability } \\
\text { Exp. } 1 \text { : agent prime vs. neutral prime } \\
\text { Exp. } 2 \text { : active prime vs. neutral prime }\end{array}$ & -.26 & .48 & -.55 & - & - & - \\
\hline
\end{tabular}

$p<.05$.

${ }^{\dagger} p<.10$.

\subsubsection{Speech onsets}

Active and passive sentences had comparable onsets (1900 and 1859 ms respectively) and onsets did not differ reliably across Prime conditions. Onsets varied only with the ease of naming the agent: sentences describing events with "easy" agents were initiated more quickly (1842 ms) than sentences with "harder" agents (1939 ms; $\beta=.12, z=2.09$, for the main effect of Agent codability). There was no interaction between Agent codability and Sentence form, suggesting that agents were encoded with priority in both active and passive sentences and thus that speakers had a strong preference for placing agents in subject position.

\subsubsection{Timecourse analyses}

Quasi-logistic regressions (performed by participants and by items) compared the proportions of agent-directed fixations across items and conditions for active sentences over time (Barr, 2008). ${ }^{5}$ Fixations were first binned into consecutive $10 \mathrm{~ms}$ time samples and then aggregated into $200 \mathrm{~ms}$ time bins. An empirical logit was calculated for each time bin indexing the log odds of speakers fixating the agent in that time bin (out of the total number of fixations to the agent, patient, and to empty areas on the screen observed in that time bin). Regressions were performed on the empirical logits.

We first tested the effect of event properties that were not manipulated experimentally by comparing the distribution of agent-directed fixations with respect to Agent codability and Event codability (Section 2.2.4.1). Codability scores were included as categorical predictors in the by-participant analyses (following a median split into higher- and lower-codability events and agents) and as continuous predictors in the by-item analyses. Next, a separate analysis compared production of sentences describing events with "easier" and "harder" agents across Prime conditions, as character codability

\footnotetext{
${ }^{5}$ Performing separate by-participant and by-item analyses is a way of compensating for the non-independence of individual fixations. Briefly, fixations to characters in an event on any given trial by the same speaker are strongly intercorrelated. Aggregating data within a condition can reduce the degree to which non-independence inflates statistical outcomes. Aggregation can be done across items and across participants, as is typically done to calculate $F 1$ and $F 2$ statistics in the ANOVA framework.
} 
and character priming were expected to produce analogous effects (Section 2.2.4.2). There were no interactions between Prime condition and Event codability, so this analysis is not reported.

Three time windows were chosen for examination in each analysis based on three theoretically important distinctions. The first time window included the period between $0 \mathrm{~ms}$ (picture onset) and $400 \mathrm{~ms}$ (i.e., two consecutive bins of $200 \mathrm{~ms}$ each): on Griffin and Bock's (2000) account, speakers may select a starting point in this time window on the basis of their construal of the gist of the event (hierarchical incrementality), or, on Gleitman et al.'s (2007) account, on the basis of non-relational properties of the two characters (linear incrementality). ${ }^{6}$ It was expected that formulation would be more hierarchically incremental in high-codability events and more linearly incremental in events with high-codability agents. Priming character names in this experiment was also expected to result in a shift towards linear incrementality.

The second and third time windows included the period between $400 \mathrm{~ms}$ and speech onset that corresponds to retrieval of the first character name (name-related gazes). This time window includes a segment with increasing fixations (400-1000 ms, i.e., three $200 \mathrm{~ms}$ time bins) and decreasing fixations to this character (1000-1800 ms in Experiment 1, and thus four $200 \mathrm{~ms}$ time bins; 1000$2200 \mathrm{~ms}$ in Experiment 2, and thus six $200 \mathrm{~ms}$ time bins). The length of gazes on the agent and thus the timing of gaze shifts from the agent to the patient were expected to reflect the ease of encoding the agent and to show when speakers were ready to begin adding the patient to the sentence.

The models included all predictors as additive factors and only interactions that contributed to model fit $(p<.10)$ and that were reliable at $p M C M C<.05$ (for models without random slopes) or $p<.05$ (for models with random slopes), unless stated otherwise. The by-item analyses had less statistical power, so interactions in these analyses that were reliable but did not improve model fit (relative to models without these interactions) are reported for comparison with the by-participant analyses. Main effects of a variable in these models indicate differences in fixations at the start of a given window (i.e., the first time bin in a given window), and interactions with the Time variable (Time bin) indicate changes in the slopes of fixations over time (i.e., changes between the first time bin and subsequent time bins in a given window).

2.2.4.1. Effects of Agent codability and Event codability. Fixations between 0 and $400 \mathrm{~ms}$. Fig. 3a and b shows the timecourse of formulation for descriptions of "easy" and "hard" events with "easy" and "hard" agents. Overall, speakers quickly directed their attention to the agent between 0 and $200 \mathrm{~ms}$ of picture onset and then briefly looked back to the patient by $400 \mathrm{~ms}$.

There were more fixations to "easy" agents than "hard" agents within $200 \mathrm{~ms}$ of picture onset (a main effect of Agent codability; Table 3a), and this difference increased in the 200-400 ms time bin (resulting in an interaction of Agent codability with Time bin). The preference for fixating "easy" agents is consistent with linear incrementality as it shows immediate effects of character-specific properties on early formulation.

Importantly, differences in the distribution of early fixations in this time window were also modulated by Event codability (resulting in an interaction between Event and Agent codability in the by-participant analysis). The difference in fixations to "easy" and "hard" agents was larger in lower-codability events than in higher-codability events: speakers were less likely to fixate "easy" agents in "easy" events than to fixate "easy" agents in "hard" events, but were more likely to fixate "hard" agents in "easy" events than to fixate "hard" agents in "hard" events. This shows sensitivity to character properties when the event is hard to encode and less sensitivity to character properties when the event is easy to encode, which is broadly consistent with hierarchical incrementality.

Fixations between 400 and $1000 \mathrm{~ms}$. Having fixated agents with priority at the outset of formulation (0-400 ms), speakers did not continue formulating sentences with an easy-to-name agent in subject position. Instead, they shifted their gaze back to the patient by $400 \mathrm{~ms}$, suggesting that they also preferred to encode information about the second character relatively early in the formulation process. Fig. 3 shows that the shift of gaze away from the agent was larger in items with "easy" agents, so there

\footnotetext{
${ }^{6}$ Quasi-logistic regressions only test for linear effects in the data. Aggregating the data into $200 \mathrm{~ms}$ bins averages over the inflection point observed at $200 \mathrm{~ms}$ (the rise in fixations observed until $200 \mathrm{~ms}$ and the fall in fixations observed before $400 \mathrm{~ms}$ ), and thus does not require adding a quadratic term to the model.
} 


\section{Experiment 1}

(a) "EASY" EVENTS

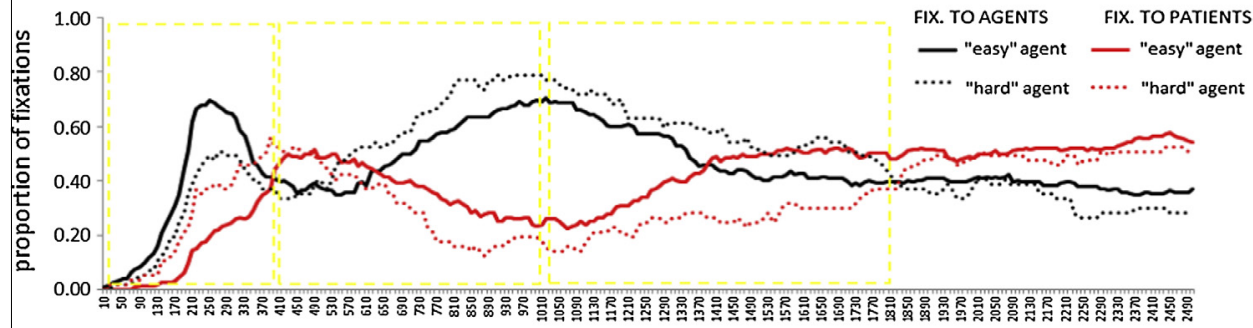

(b) "HARD" EVENTS

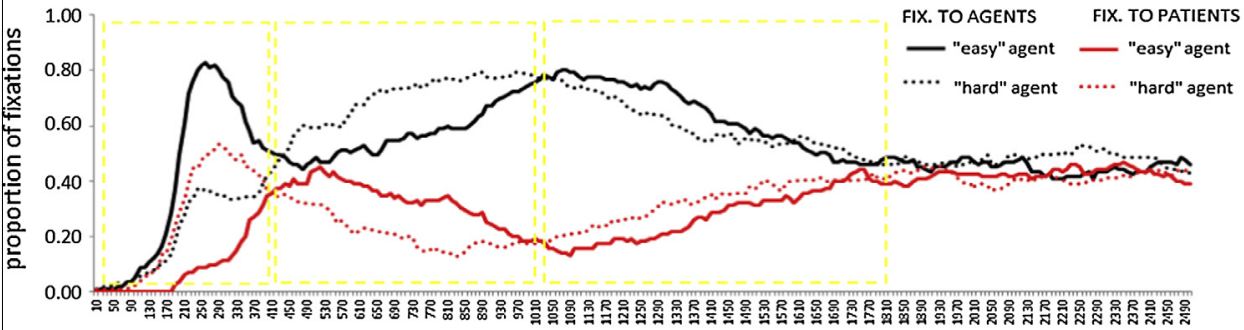

\section{Experiment 2}

(c) "EASY" EVENTS

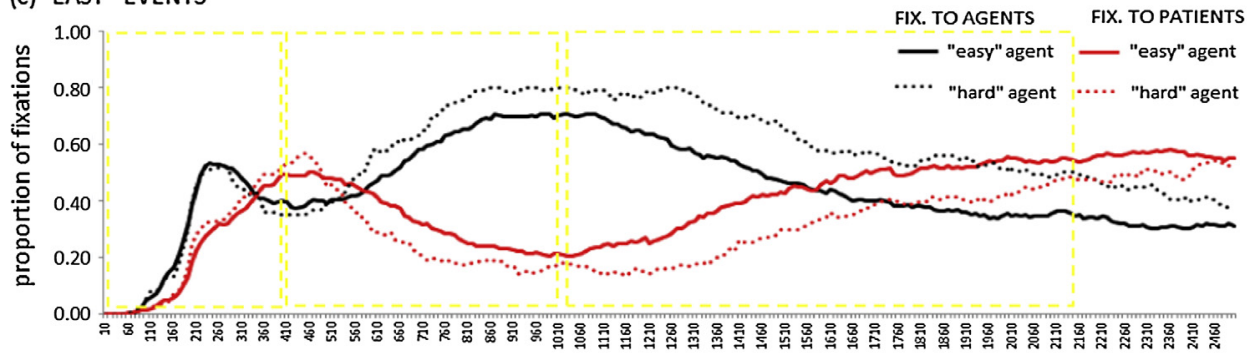

d) "HARD" EVENTS

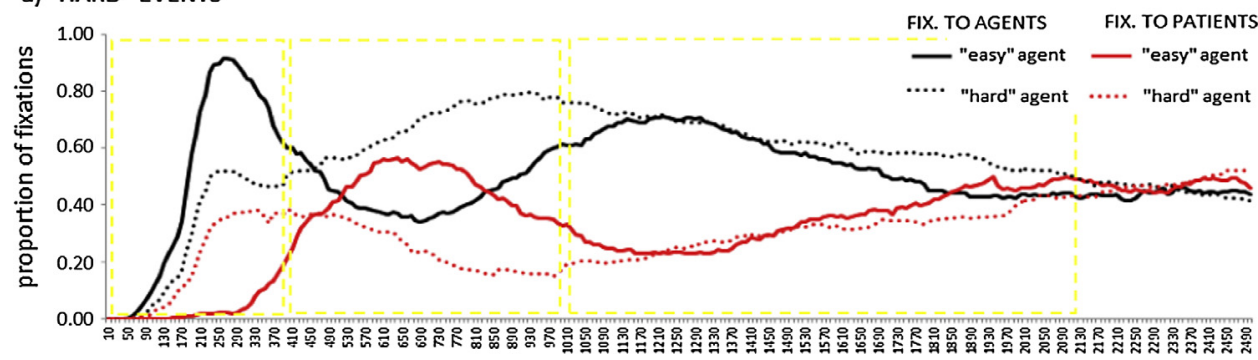

Fig. 3. Timecourse of formulation for active sentences in Experiment 1 and 2 with respect to Event codability ("easy" vs. "hard" events) and Agent codability ("easy" vs. "hard" agents).

were fewer fixations to "easy" agents than "hard" agents at the start of the 400-1000 ms time window (i.e., at 400-600 ms; a main effect of Agent codability; Table 3b). In contrast, when speakers fixated agents to a lesser extent before $400 \mathrm{~ms}$ ("hard" agents), they were more likely to immediately turn their gaze to the agent after $400 \mathrm{~ms}$. 


\section{Table 3}

Results of regressions comparing fixations to the agent in active sentences describing "easier" and "harder" events with "easier" and "harder" agents in Experiment 1. (s) indicates the inclusion of random slopes, (a) indicates that the effect does not reliably improve model fit.

\begin{tabular}{|c|c|c|c|c|c|c|}
\hline \multirow[t]{2}{*}{ Effect } & \multicolumn{3}{|c|}{ By-participants } & \multicolumn{3}{|l|}{ By-items } \\
\hline & Est. & SE & $t$-Value & Est. & SE & $t$-Value \\
\hline \multicolumn{7}{|l|}{ (a) $0-400 \mathrm{~ms}$} \\
\hline Intercept & -1.70 & .05 & $-34.93^{*}$ & -2.02 & .02 & $-88.49^{*}$ \\
\hline Time bin & $9.16(\mathrm{~s})$ & .25 & $37.22^{*}$ & $10.34(\mathrm{~s})$ & .14 & $72.50^{*}$ \\
\hline Event codability & -.41 & .07 & $-6.06^{*}$ & -.12 & .03 & $-4.30^{*}$ \\
\hline Agent codability & -.26 & .07 & $-3.52^{*}$ & -.14 & .03 & $-4.77^{*}$ \\
\hline Time bin $*$ Event codability & 2.20 & .41 & $5.37^{*}$ & 1.20 & .18 & $6.72 *(a)$ \\
\hline Time bin $*$ Agent codability & -2.98 & .44 & $-6.74^{*}$ & -1.93 & .18 & $-10.82^{*}(\mathrm{a})$ \\
\hline Event codability $*$ Agent codability & -.62 & .10 & $-6.44^{*}$ & .05 & .04 & 1.23 \\
\hline \multicolumn{7}{|l|}{ (b) $400-1000 \mathrm{~ms}$} \\
\hline Intercept & -.14 & .02 & $-6.08^{*}$ & -.26 & .02 & $-13.65^{*}$ \\
\hline Time bin & 1.66 & .09 & $18.54^{*}$ & 2.79 & .05 & $55.23^{*}$ \\
\hline Event codability & .41 & .05 & $8.82^{*}$ & .24 & .03 & $9.61^{*}$ \\
\hline Agent codability & .25 & .04 & $7.05^{*}$ & .28 & .02 & $14.07^{*}$ \\
\hline Time bin $*$ Event codability & -1.49 & .18 & $-8.32^{*}$ & -.78 & .07 & $-11.09^{*}(a)$ \\
\hline \multicolumn{7}{|l|}{ (c) $1000-1800 \mathrm{~ms}$} \\
\hline Intercept & .55 & .03 & $20.37^{*}$ & .90 & .02 & $57.07^{*}$ \\
\hline Time bin & -1.15 & .06 & $-20.22^{*}$ & $-1.61(\mathrm{~s})$ & .04 & $-44.47^{*}$ \\
\hline Event codability & .15 & .04 & $4.19^{*}$ & .30 & .02 & $20.00^{*}$ \\
\hline Agent codability & .05 & .04 & 1.42 & .36 & .01 & $26.13^{*}$ \\
\hline Event codability $*$ Agent codability & -.24 & .07 & $-3.26(a)$ & -.29 & .02 & $-14.53^{*}$ (a) \\
\hline
\end{tabular}

Between 400 and $1000 \mathrm{~ms}$, speakers deployed their gaze to the agent in events with "easy" and "hard" agents alike. There was no interaction between Agent codability and Time bin, indicating that the slope of fixations in events with "easy" and "hard" agents did not change over time: speakers continued fixating "harder" agents more than "easier" agents until $1000 \mathrm{~ms}$.

At the start of the 400-1000 ms time window (i.e., 400-600 ms), speakers were also less likely to fixate agents in "easier" events than "harder" events (a main effect of Event codability). An interaction with Time bin shows that fixations to the agent subsequently increased more quickly in "easier" events than "harder" events.

Fixations between 1000 and $1800 \mathrm{~ms}$ (speech onset). Speakers began looking away from the agent approximately $1000 \mathrm{~ms}$ after picture onset, and the cross-over point after which they started fixating the patient preferentially occurred approximately $1800 \mathrm{~ms}$ into the trial (i.e., around speech onset).

Comparing Fig. 3a and b shows that, at 1000-1200 ms, speakers were less likely to fixate agents in "easy" events than in "hard" events (a main effect of Event codability; Table 3c): in addition, speakers were less likely to fixate "easy" agents in "easy" events but still fixated "easy" agents in "hard" events (producing a weak interaction of Event and Agent codability; Table 3c). There were no interactions with Time bin, indicating that the decline in agent-directed fixations after $1000 \mathrm{~ms}$ was comparable across event categories. However, since the peak in fixations to the agent occurred earlier in "easy" events than "hard" events, the shift of gaze to the patient also occurred earlier in "easy" events than "hard" events. On the hypothesis that high Event codability favors faster encoding of relational information in the event (hierarchical incrementality), this result suggests that speakers began adding information about the second character to the developing sentence earlier when the relationship between characters was easier to encode than when it was harder to encode. 
Fixations between 0 and $400 \mathrm{~ms}$. Again, speakers directed more fixations to "easier" agents than "harder" agents within $200 \mathrm{~ms}$ of picture onset (a main effect of Agent codability; Table 4a) and then briefly looked back to the patient by $400 \mathrm{~ms}$. An interaction with Time bin was observed only in the

\section{Experiment 1}

(a) "EASY" AGENTS

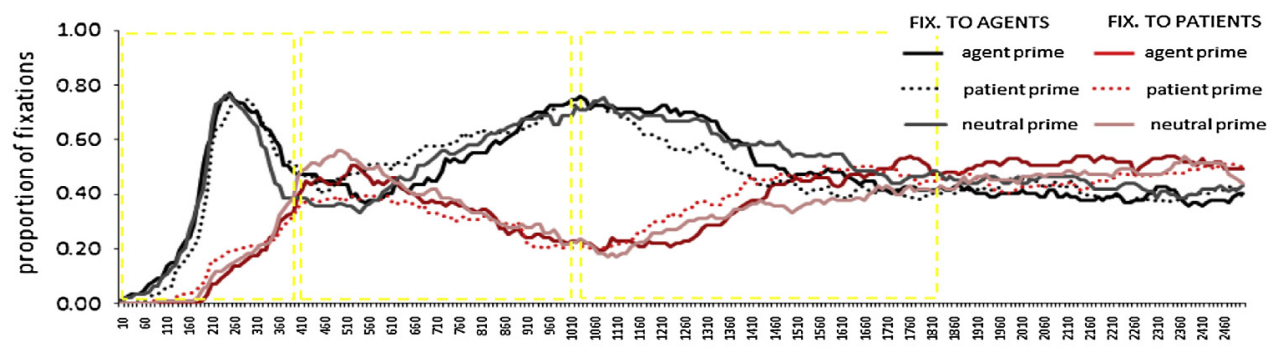

(b) "HARD" AGENTS

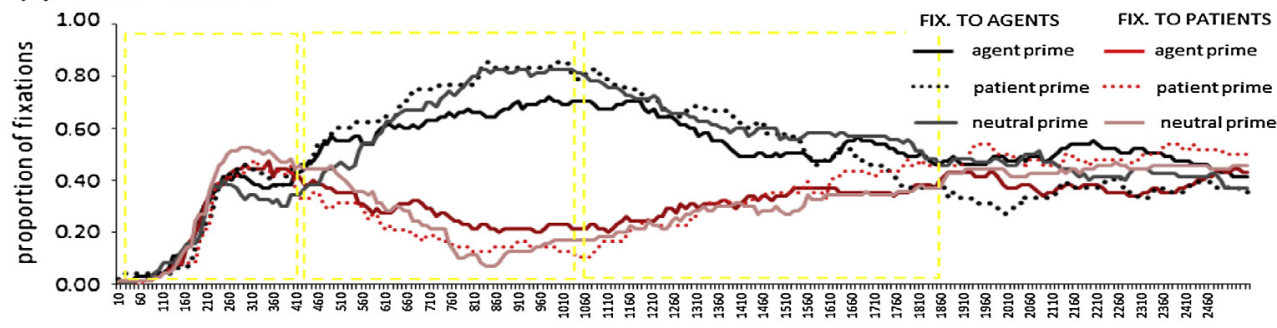

Experiment 2

(c) "EASY" AGENTS

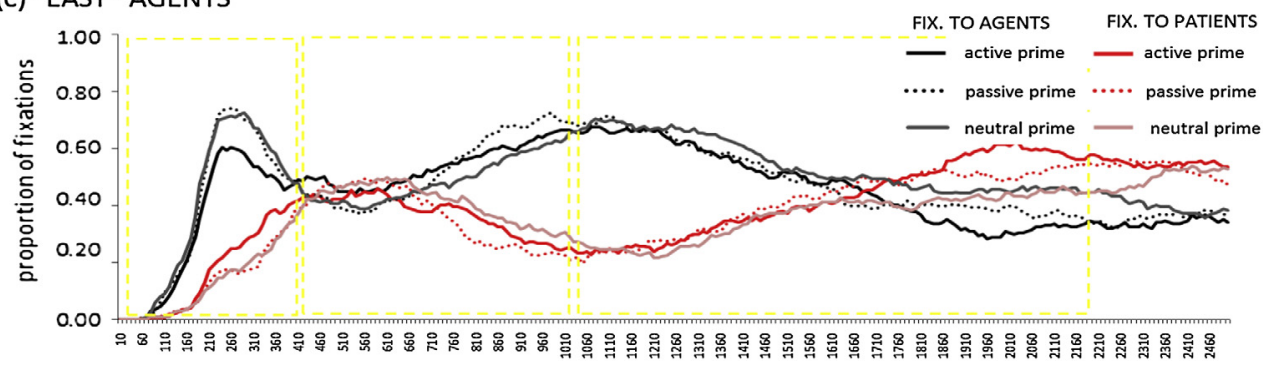

(d) "HARD" AGENTS

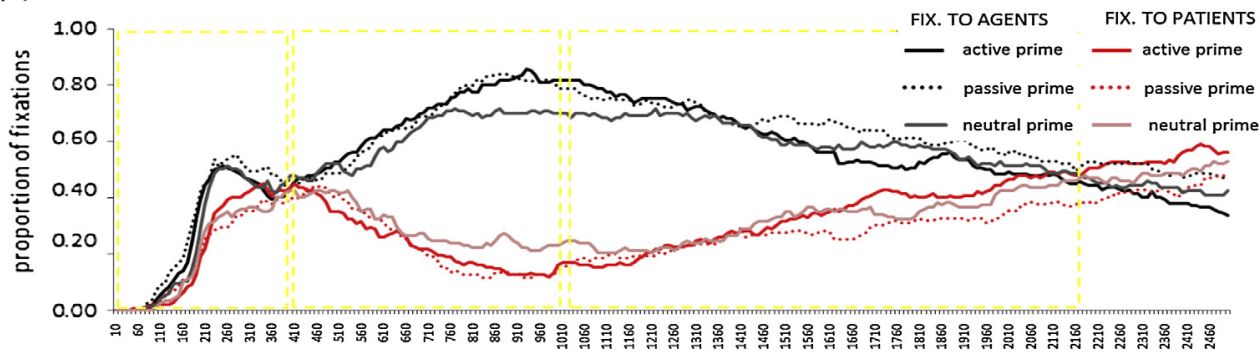

Fig. 4. Timecourse of formulation for active sentences in Experiments 1 and 2 with respect to Agent codability ("easy" vs. "hard" agents) and Prime condition. 


\section{Table 4}

Results of regressions comparing fixations to the agent in active sentences with "easy" and "hard" agents across Prime conditions in Experiment 1.

\begin{tabular}{|c|c|c|c|c|c|c|}
\hline \multirow[t]{2}{*}{ Effect } & \multicolumn{3}{|c|}{ By-participants } & \multicolumn{3}{|l|}{ By-items } \\
\hline & Est. & SE & $t$-Value & Est. & SE & $t$-Value \\
\hline \multicolumn{7}{|l|}{ (a) $0-400 \mathrm{~ms}$} \\
\hline Intercept & -1.55 & .04 & $-36.64^{*}$ & -1.88 & .03 & $-58.12^{*}$ \\
\hline Time bin & 8.48 & .25 & $34.35^{*}$ & $9.61(\mathrm{~s})$ & .24 & $39.44^{*}$ \\
\hline Agent codability & -.69 & .05 & $-13.00^{*}$ & -.11 & .04 & $-2.96^{*}$ \\
\hline Prime condition: neutral primes vs. other primes & .10 & .05 & $1.86^{\dagger}$ & -.18 & .04 & $-4.56^{*}$ \\
\hline Prime condition: agent primes vs. patient primes & -.13 & .06 & $-2.08^{*}$ & -.42 & .05 & $-8.81^{*}$ \\
\hline Time bin $*$ Agent codability & - & - & - & -2.09 & .30 & $-6.96^{*}$ \\
\hline Time bin $*$ Prime condition: neutral primes vs. other primes & - & - & - & 1.77 & .29 & $6.11^{*}$ \\
\hline Time bin $*$ Prime condition: agent primes vs. patient primes & - & - & - & 2.39 & .36 & $6.72^{*}$ \\
\hline \multicolumn{7}{|l|}{ (b) $400-1000 \mathrm{~ms}$} \\
\hline Intercept & -.09 & .03 & $-2.79^{*}$ & -.29 & .03 & $-8.81^{*}$ \\
\hline Time bin & 1.57 & .12 & $13.36^{*}$ & $2.53(\mathrm{~s})$ & .09 & $27.03^{*}$ \\
\hline Agent codability & .29 & .05 & $6.49^{*}$ & .20 & .04 & $5.14^{*}$ \\
\hline Prime condition: neutral primes vs. other primes & $.06(\mathrm{~s})$ & .05 & 1.19 & .05 & .02 & $2.38^{*}$ \\
\hline Prime condition: agent primes vs. patient primes & $.15(\mathrm{~s})$ & .06 & $2.43^{*}$ & .27 & .03 & $9.99^{*}$ \\
\hline Time bin $*$ Agent codability & - & - & - & .37 & .11 & $3.35^{*}(\mathrm{a})$ \\
\hline \multicolumn{7}{|l|}{ (c) $1000-1800 \mathrm{~ms}$} \\
\hline Intercept & .54 & .03 & $16.60^{*}$ & .77 & .03 & $30.00^{*}$ \\
\hline Time bin & -1.06 & .08 & $-14.05^{*}$ & -1.53 & .06 & $-25.07^{*}$ \\
\hline Agent codability & .09 & .04 & $2.30^{*}$ & .23 & .02 & $10.12^{*}$ \\
\hline Prime condition: neutral primes vs. other primes & -.16 & .04 & $-4.31^{*}$ & -.19 & .02 & $-9.42^{*}$ \\
\hline Prime condition: agent primes vs. patient primes & -.03 & .05 & -.74 & -.12 & .02 & $-5.10^{*}$ \\
\hline
\end{tabular}

${ }^{*} p<.05$.

$+p<.10$.

by-item analysis, showing that fixations to "easier" agents rose somewhat more steeply over time in this time window than fixations to "harder" agents.

Supporting linear incrementality, there were also more fixations to the agent after agent and patient primes ("other" primes) than after neutral primes (the first contrast for Prime condition in the by-participant analysis) and more fixations to the agent after agent primes than patient primes (the second contrast for Prime condition in the by-participant analysis). The by-item analysis additionally showed that fixations to agents increased more rapidly after "other" primes than after neutral primes and more rapidly after patient primes than agent primes (the first and second contrast respectively in the interaction of Prime condition with Time bin). There was no interaction between Prime condition and Agent codability.

Fixations between 400 and $1000 \mathrm{~ms}$. After fixating "easier" agents preferentially before $400 \mathrm{~ms}$, speakers began looking away from "easier" agents. At 400-600 ms, there were thus fewer fixations to "easy" agents than "hard" agents (resulting in a main effect of Agent codability; Table $4 \mathrm{~b}$ ), and this difference persisted over the entire 400-1000 ms time window (an interaction with Time bin was observed only in the by-item analysis).

An effect of Prime condition was present in this time window as well. After fixating agents more often after agent primes before $400 \mathrm{~ms}$, speakers were also somewhat more likely to look away from the agent after agent primes and patient primes than after neutral primes (the first contrast for Prime condition; Table 4b). This effect was mainly driven by a difference between the agent prime and patient prime conditions (the second contrast for Prime condition) and shows that priority encoding of a character agent before $400 \mathrm{~ms}$ was followed by a larger shift away from this character after $400 \mathrm{~ms}$. Overall, this pattern demonstrates a strong tendency for character-by-character encoding during formulation of the target sentences. There were no interactions of Prime condition with Agent codability or Time bin.

Fixations between 1000 and 1800 ms (speech onset). "Easy" agents were faster to encode, so speakers were less likely to fixate "easy" agents than "hard" agents at 1000-1200 ms. There was no interaction 
with Time bin, so the difference between "easy" and "hard" agents persisted across the entire time window. In addition, there were fewer fixations to agents after agent primes and patient primes ("other" primes) than after neutral primes (the first contrast for Prime condition; Table 4c), suggesting that priming of either character resulted in an earlier shift of gaze to the patient. A differences in fixation patterns after agent primes and patient primes was reliable only in the by-item analyses (the second contrast for Prime condition), showing fewer fixations to agents after agent primes. There were no interactions with Agent codability or Time bin.

\subsection{Discussion}

Experiment 1 showed that sentence form was influenced in different ways by non-relational and relational variables and that the timecourse of formulation reflected these differences.

On the one hand, there was an expected effect of character codability and lexical priming on sentence form: speakers produced accessible characters ("easy" agents and patients) before less accessible characters in their sentences. This confirms that ease of naming can determine the suitability of individual characters for starting points and is broadly consistent with linear incrementality. On the other hand, comparing the agent and patient prime conditions against the neutral prime condition shows that priming effects after agent and patient primes were asymmetrical: agent primes did not reliably increase production of active sentences whereas patient primes reduced the probability of selecting an active structure. Thus manipulating the accessibility of a character that speakers normally produce in object position (the patient) produced a larger change than manipulating the accessibility of a character that is more often selected as the sentence subject (the agent). An interaction with Agent codability additionally showed that the influence of patient primes was stronger in events with harder-to-name agents than easier-to-name agents: speakers were more likely to postpone production of a "hard" agent than an "easy" agent when the patient had been primed.

Given that stronger priming effects are normally obtained for less frequent than more frequent lexical items and for dispreferred than preferred structures (see Ferreira \& Bock, 2006), the results demonstrate that speakers have a strong preference for treating agents as "default" subjects. The implication of this result for theories of formulation is that accessibility effects are modulated by higher-level, relational information: in order to prioritize encoding of the agent, speakers first had to identify the two characters in terms of their event roles. The degree to which identification of agents requires extensive encoding of event gist is debatable because of lower-level perceptual correlates of "agenthood" (Hafri et al., 2012); nevertheless, selection of starting points appears to be sensitive to a combination of non-relational and relational variables.

Consistent with this conclusion is also the effect of Event codability on sentence form. The influence of patient primes was stronger in "harder" than "easier" events: the patient primes reduced the likelihood of selecting the preferred active structure to describe "hard" events, suggesting that increasing the accessibility of patient names increased their suitability for starting points in cases where properties of the event did not facilitate selection of a starting point on conceptual grounds. Character accessibility played a smaller role in "easier" events, or events where speakers could initiate production without relying on properties of the two characters to select a starting point. The direction of this effect is consistent with Kuchinsky and Bock's (2010) finding that drawing attention to one character is less likely to bias assignment of this character to subject position in "easier" than "harder" events.

More importantly, we tested whether these differences in non-relational and relational encoding also produced different patterns of eye movements across items and conditions before speech onset. The first test of incrementality is the analysis of first fixations, and the results were consistent with linear incrementality: the first-fixated character was more likely to become the sentence subject than the other character. This replicates studies using cuing paradigms to test the effect of gaze shifts on sentence form (Gleitman et al., 2007, Kuchinsky \& Bock, 2010) without a direct manipulation of perceptual salience and attention capture.

The second test of incrementality is the analysis of eye movements to event characters throughout the formulation process. Timecourse analyses showed a combination of accessibility effects and effects of relational variables on formulation. Eye movements in the first time window (0-400 ms) 
showed immediate sensitivity to properties of the agents: speakers directed their gaze towards "easier" agents and away from "harder" agents. Importantly, effects of Agent codability were modulated by the ease of encoding event gist (Event codability): Agent codability had a weaker influence in "easy" events than "hard" events, suggesting that properties of the event can constrain the effects of character-specific variables. This shows higher sensitivity to relational than non-relational information, consistent with hierarchical incrementality.

Fast encoding of an "easy" agent before $400 \mathrm{~ms}$ was then followed by a shift of attention to the patient around $400 \mathrm{~ms}$. In other words, speakers did not continue fixating the subject character after $400 \mathrm{~ms}$ as predicted by the strong version of linear incrementality (Gleitman et al., 2007), but systematically shifted their gaze back to the patient. This type of character-by-character encoding is consistent with a weaker version of linear incrementality, where speakers do attempt to encode information about both characters early in the formulation process but, crucially, they encode this information sequentially. Thus the rise and fall of fixations to the agent after $400 \mathrm{~ms}$ was also predicted by Agent codability: fixations to agents were generally delayed after $400 \mathrm{~ms}$ if agents attracted more attention before $400 \mathrm{~ms}$, and vice versa. Specifically, formulation in events with "harder" agents showed that there is a benefit to distributing attention more evenly between the two characters before $400 \mathrm{~ms}$ : formulation after $400 \mathrm{~ms}$ continued with rapid, preferential encoding of the agent. Importantly, shifts of gaze to the agent after $400 \mathrm{~ms}$ and away from the agent after $1000 \mathrm{~ms}$ were also influenced by Event codability: as predicted by hierarchical incrementality, speakers began fixating the patient earlier in higher-codability events than lower-codability events.

As expected, the lexical primes produced analogous effects to Agent codability: within $400 \mathrm{~ms}$ of picture onset, speakers directed more fixations to the agent after agent primes than after patient primes and neutral primes. This shows that the agent primes selectively influenced encoding of the agent character and that they increased the likelihood of speakers prioritizing encoding of this character (non-relational information) shortly after picture onset. A shift of gaze away from the agent was then observed after $400 \mathrm{~ms}$, confirming the tendency to encode sentences character by character after priming non-relational information. Finally, after $1000 \mathrm{~ms}$ speakers looked at the agent for less time after agent and patient primes than neutral primes, and thus shifted their gaze to the patient earlier when either character had been primed than when the primes mentioned an unrelated character.

Taken together, the results show a direct link between the ease of encoding non-relational and relational information and the timecourse of formulation, both during the early deployment of attention to the subject character and then the deployment of attention to the object character around speech onset. Effects of event codability generally favor hierarchical incrementality, while pervasive effects of character accessibility on formulation - originating both in pre-existing properties of the event characters and in experimentally manipulated accessibility - generally favor linear incrementality. The next experiment tested whether experimentally facilitating relational encoding via structural priming produces a shift in planning in the opposite direction to that obtained in Experiment 1 with a manipulation of the ease of non-relational encoding.

\section{Experiment 2}

Speakers completed a similar task in the second experiment. Target pictures included a nearly identical set of two-character transitive events as that of Experiment 1. Formulation of active sentences was again compared from picture onset until speech onset with respect to one variable influencing encoding of individual characters (character codability) and one variable influencing relational encoding (event codability). Effects of character codability and event codability were expected to replicate Experiment 1.

On the hypothesis that relational encoding also depends on the ease of generating a syntactic structure, the ease of structural assembly was manipulated by exposing speakers to three types of structural primes before target trials. On one third of all prime trials, speakers saw a picture of a transitive event that was accompanied by a recorded active sentence, and on one third of all trials, they saw the same picture accompanied by a recorded passive description. Active and passive syntax was thus either primed or unprimed. On the remaining third of prime trials, speakers saw pictures 
where multiple referents were engaged in a joint action and heard an intransitive sentence (e.g., The couple are roller-skating). This condition served as a baseline to assess the overall likelihood of using active and passive syntax.

If the ease of structural assembly influences the timecourse of sentence formulation, speakers should be more likely to engage in hierarchically incremental planning when using primed structures than unprimed structures. Specifically, if fast generation of an "easy" structure facilitates encoding of relational information about the event (i.e., the relationship between two characters), fixations to agents and patients should diverge more slowly in the first $400 \mathrm{~ms}$ of picture inspection in primed sentences compared to unprimed sentences. This is analogous to the effect of Event codability on early formulation. Having encoded relational information in primed sentences before $400 \mathrm{~ms}$, fixations to the two characters after $400 \mathrm{~ms}$ should then show evidence of top-down structural guidance: speakers should direct their gaze to the agent more quickly in primed than unprimed sentences after $400 \mathrm{~ms}$ and should begin shifting their gaze to the patient earlier in primed than primed sentences around speech onset.

\subsection{Method}

\subsubsection{Participants}

Eighty-four native speakers of Dutch (mostly university students; 64 female) from the Nijmegen area participated for payment. Seven participants were replaced because of low response rates and seven because of technical problems. The sample was larger than in Experiment 1 because participants also took part in a second, unrelated study.

\subsubsection{Materials, design, and procedure}

As in Experiment 1, there were four types of trials: target trials, prime trials, filler trials, and word trials. On target trials, participants saw pictures of two-character transitive events (26 pictures used in Experiment 1 and 4 new pictures) and were asked to describe them in one sentence. There were 21 items with animate agents (13 items with human agents, 8 with animal agents), and 9 with inanimate agents. Twenty-two items had animate patients (19 items had human patients, 3 had animal patients) and 8 had inanimate patients.

Target pictures were preceded by three types of prime trials. In the active and passive prime conditions, speakers saw new pictures of two-character transitive events accompanied by a recorded active or passive description. In the neutral prime condition, they saw pictures of two-character (or multi-character) intransitive events accompanied by a recorded intransitive description.

The design included one three-level factor (Prime condition: active primes, passive primes, neutral primes). Two versions of each target picture were created to counterbalance the location of agents and patients in each picture on the left and right hand-side of the screen, but all analyses collapsed across this factor. The procedure and list structure were analogous to Experiment 1.

\subsubsection{Sentence scoring}

The same scoring criteria were applied as in Experiment 1. Two items were excluded from the analyses because they elicited a very low number of scorable responses. Responses were also excluded if the first fixation in the trial did not fall on the fixation point at the top of the screen (144 trials), if latencies were longer than $5.5 \mathrm{~s}$ and longer than 3 standard deviations away from the grand mean (28 sentences; the $5.5 \mathrm{~s}$ cutoff is higher than in Experiment 1 because sentence onsets were on average longer than in the first experiment). After applying these criteria, there were 1405 trials (.68 actives, .32 full passives) left for the analyses of structure choice and for the timecourse analyses. Excluding disfluent responses left 1334 trials for the analysis of speech onsets.

\subsubsection{Character codability and Event codability scoring}

Codability ratings were calculated as in Experiment 1. Again, Event codability was not correlated with either Agent or Patient codability $(r=.18$ and $-.27, n s$., respectively), confirming that encoding of the relational structure of an event did not depend on fast identification and naming of individual characters. Event codability ratings did not differ across Prime conditions (all $p s>.9$ ), showing that the 
structural primes did not influence speakers' verb choice and thus did not contribute further to variability in event descriptions. Agent and Patient codability were again positively correlated $(r=.45$, $p<.05$ ). Since Patient codability (residualized on Agent codability) did not reliably influence structure choice, this factor was excluded from all analyses.

\subsubsection{Analyses}

Analyses were conducted as in Experiment 1 and considered effects of First fixations (Section 3.2.1) and structural primes on sentence form (Section 3.2.2) across items and conditions, differences in speech onsets across items and conditions (Section 3.2.3), and the timecourse of formulation (Section 3.2.4) for active sentences.

\subsection{Results}

\subsubsection{First fixations and sentence form}

The majority of first fixations were directed to the agent (.68), as in Experiment 1, and the distribution of first fixations was influenced by structural primes: speakers directed fewer fixations to the agent at picture onset after active primes (.64) than after other primes (neutral and patient primes; 70 and .71 respectively, $\beta=-.50, z=-3.03$ ). The neutral and passive prime conditions did not differ $(\beta=.05, z=.25$ ). Thus unlike the lexical primes in Experiment 1, the influence of structural primes on visual inspection of a pictured event was not to direct speakers' gaze to the agent after active primes and to the patient after passive primes: in other words, structural primes did not prime selection of a particular character as a starting point.

First fixations were also weaker predictors of sentence form than in Experiment 1 (Fig. $1 \mathrm{~b}$ and c). Fig. 1b shows that the degree to which first fixations influenced structure choice was modulated by the structural primes. Speakers produced more active sentences if they looked first at the agent rather than at the patient after neutral primes and passive primes; this pattern was reversed after active primes, where speakers produced actives after both agent-directed and patient-directed first fixations. In addition, the effect of active primes on structure selection was stronger in "easier" events (Fig. 1c), where speakers produced actives even after first looking at the patient, than in "harder" events, where speakers were generally more likely to assign a first-fixated character to subject position. This resulted in a three-way interaction between First Fixations, Prime condition, and Event codability $(\beta=-1.09$, $z=-2.19$, with random by-participant slopes for First Fixations and Prime condition, and random by-item slopes for Prime condition; the interaction was reliable but did not improve model fit). In other words, the two variables influencing the ease of relational encoding (Event codability and structural priming) reduced the impact of first fixations on selection of a sentence structure.

\subsubsection{Structural primes, codability, and sentence form}

Fig. 2a shows the proportions of active sentences produced in the three Prime conditions. Speakers produced fewer active sentences after passive primes than after other primes (active and neutral primes; the first contrast for Prime condition in Table 2). Production of actives after active primes and neutral primes was comparable: relative to the neutral baseline condition, active primes did not increase likelihood of speakers producing active sentences (the second contrast for Prime condition in Table 2). In other words, the effectiveness of active primes was considerably weaker than the effectiveness of passive primes, confirming the observation that the magnitude of priming is larger for the less frequent construction (Ferreira \& Bock, 2006).

Agent codability had the expected effect on sentence form: speakers produced more active sentences beginning with "easy" agents than "hard" agents (.71 vs. .61). Importantly, Agent codability interacted with Prime condition (Fig. 2b; Table 2). The first contrast for this interaction shows no difference between production of actives in the passive condition and in the two other conditions in items with "easy" and "hard" agents. However, the second contrast shows a difference between the active prime condition and neutral prime condition: this is due to the fact that active primes increased the likelihood of speakers placing a "harder" agent in subject position. In other words, the effect of agent accessibility on sentence form was attenuated by structural priming: active primes selectively increased production of active descriptions in items where properties of the agent disfavored selection 
of active syntax. The direction of this effect is again consistent with the observation that priming effects are larger when structures are difficult to produce ("difficulty" in this case is defined by the conflict between the preference to begin sentences with agents and the preference to produce less accessible referents later).

Structure choice was not sensitive to Event codability (Fig. 2c). Speakers tended to produce more active sentences to describe "harder" events, and, while passive primes reduced this tendency, interactions with Prime condition did not reach significance.

\subsubsection{Speech onsets}

Active sentences were initiated earlier than passive sentences ( $2029 \mathrm{~ms} v \mathrm{vs} .2131 \mathrm{~ms}$ ). As in Experiment 1, onsets were sensitive to Agent codability: sentences with "easier" agents were initiated more quickly than sentences with "harder" agents ( $\beta=.16, z=3.51$, for the main effect of Agent codability), but this effect was smaller in passive sentences, where agents were produced in object position ( $\beta=.08, z=2.18$, for the interaction of Sentence type with Agent codability). Thus speakers likely attempted to encode agents as sentence subjects by default, but demonstrated more sensitivity to properties of the second character than in Experiment 1.

Speech onsets differed across Prime conditions only in active sentences. Onsets were longer after passive primes than after active and neutral primes combined $(\beta=.08, z=2.98)$; onsets after active and neutral primes did not differ $(\beta=.01, z=.22)$. Onsets in passive sentences did not vary by condition, but interactions of Sentence type (active vs. passive) with Prime condition did not reach significance.

\subsubsection{Timecourse analyses}

As in Experiment 1, speakers began formulation of active sentences by fixating agents preferentially within $200 \mathrm{~ms}$ of picture onset and then briefly directing their gaze to the patient by $400 \mathrm{~ms}$. They redeployed attention to agents after $400 \mathrm{~ms}$ and continued fixating this character until speech onset.

Analyses were carried out in three steps. The first analysis compared formulation of sentences for events varying in Event codability and Agent codability (Section 3.2.4.1). The second analysis examined formulation of sentences with "easy" and "hard" agents across Prime conditions (Section 3.2.4.2), and the third analysis examined formulation of sentences describing "easy" and "hard" across Prime conditions (Section 3.2.4.3). Three time windows were chosen for examination within each analysis: 0-400 ms, 400-1000 ms (showing an increase in agent-directed fixations), 1000-2200 ms (i.e., speech onset; showing a decrease in agent-directed fixations).

3.2.4.1. Effects of Agent codability and Event codability. Fixations between 0 and $400 \mathrm{~ms}$. Fig. 3c and d shows the timecourse of formulation for descriptions of "easy" and "hard" events with "easy" and "hard" agents. The best-fitting model included a three-way interaction between Event codability, Agent codability, and Time bin (Table 5a). As in Experiment 1, speakers generally preferred to fixate "easy" agents at and shifted their gaze away from "hard" agents in search of an alternative starting point (producing an interaction of Agent codability with Time bin), consistent with linear incrementality. Event codability had the opposite effect: speakers distributed their gaze more evenly between agents and patients in "easy" events but directed more fixations to agents than patients in "hard" events. Critically, the three-way interaction shows that the effect of Agent codability depended on properties of the event. The difference between fixations directed to "easy" and "hard" agents was relatively small in "easy" events (Fig. 3c) and larger in "hard" events (Fig. 3d): here, fixations to an easy-to-name agent rose more quickly than to a harder-to-name agent. Thus speakers showed more sensitivity to properties of the agent when the relational structure of the event was harder to encode, which is broadly consistent with hierarchical incrementality.

Interestingly, as in Experiment 1, the shift of gaze away from the agent before $400 \mathrm{~ms}$ in items with "easy" agents suggests that fast selection of a starting point was likely insufficient to continue formulation without encoding information about the patient.

Fixations between 400 and $1000 \mathrm{~ms}$. Following from differences in the distribution of fixations across items observed immediately after picture onset, speakers were less likely to fixate "easy" agents than 


\section{Table 5}

Results of regressions comparing fixations to the agent in active sentences describing "easier" and "harder" events with "easier" and "harder" agents in Experiment 2.

\begin{tabular}{|c|c|c|c|c|c|c|}
\hline \multirow[t]{2}{*}{ Effect } & \multicolumn{3}{|c|}{ By-participants } & \multicolumn{3}{|l|}{ By-items } \\
\hline & Est. & SE & $t$-Value & Est. & SE & $t$-Value \\
\hline \multicolumn{7}{|l|}{ (a) $0-400 \mathrm{~ms}$} \\
\hline Intercept & -1.84 & .03 & $-61.61^{*}$ & -2.03 & .01 & $-190.52^{*}$ \\
\hline Time bin & $10.52(\mathrm{~s})$ & .18 & $59.40^{*}$ & $11.82(\mathrm{~s})$ & .11 & $109.22^{*}$ \\
\hline Event codability & .24 & .04 & $6.48^{*}$ & .27 & .01 & $21.88^{*}$ \\
\hline Agent codability & -.33 & .04 & $-8.53^{*}$ & -.21 & .01 & $-17.46^{*}$ \\
\hline Time bin $*$ Event codability & 2.67 & .23 & $11.42^{*}$ & .94 & .13 & $7.01^{*}(\mathrm{a})$ \\
\hline Time bin $*$ Agent codability & -1.76 & .24 & $-7.32^{*}$ & -1.27 & .11 & $-11.18^{*}(\mathrm{a})$ \\
\hline Event codability $*$ Agent codability & -.78 & .08 & $-9.85^{*}$ & -.18 & .01 & $-12.59^{*}(\mathrm{a})$ \\
\hline Time bin $*$ Event cod. $*$ Agent cod. & -2.67 & .49 & $-5.46^{*}$ & -.52 & .15 & $-3.53^{*}(\mathrm{a})$ \\
\hline \multicolumn{7}{|l|}{ (b) $400-1000 \mathrm{~ms}$} \\
\hline Intercept & -.15 & .02 & $-9.34^{*}$ & -.29 & .02 & $-15.52^{*}$ \\
\hline Time bin & $1.75(\mathrm{~s})$ & .07 & $26.48^{*}$ & 2.80 & .03 & $80.52^{*}$ \\
\hline Event codability & .24 & .03 & $8.70^{*}$ & -.01 & .02 & -.29 \\
\hline Agent codability & .23 & .03 & $7.97^{*}$ & .11 & .02 & $5.55^{*}$ \\
\hline Time bin $*$ Event codability & -1.70 & .11 & $-14.87^{*}$ & -.63 & .04 & $-14.81^{*}(\mathrm{a})$ \\
\hline Time bin $*$ Agent codability & 1.22 & .12 & $10.06^{*}$ & 1.12 & .04 & $28.49^{*}$ \\
\hline Event cod. $*$ Agent codability & .58 & .04 & $13.77^{*}$ & -.06 & .02 & $-2.32^{*}(\mathrm{a})$ \\
\hline \multicolumn{7}{|l|}{ (c) $1000-2200 \mathrm{~ms}$} \\
\hline Intercept & .62 & .02 & $30.82^{*}$ & .94 & .01 & $72.58^{*}$ \\
\hline Time bin & $-.91(\mathrm{~s})$ & .03 & $-29.32^{*}$ & $-1.19(\mathrm{~s})$ & .01 & $-88.23^{*}$ \\
\hline Event codability & -.07 & .03 & $-2.35^{*}$ & -.08 & .02 & $-4.75^{*}$ \\
\hline Agent codability & .30 & .02 & $16.29^{*}$ & .33 & .01 & $35.03^{*}$ \\
\hline Time bin $*$ Event codability & .35 & .05 & $6.37^{*}$ & .29 & .02 & $17.68^{*}(a)$ \\
\hline Event codability $*$ Agent codability & -.30 & .04 & $-8.08^{*}$ & -.06 & .01 & $-4.40^{*}(\mathrm{a})$ \\
\hline
\end{tabular}

${ }^{*} p<.05$.

"hard" agents and less likely to fixate agents in "easy" than "hard" events at 400-600 ms (main effects of Agent and Event codability respectively; Table 5b). The two factors interacted: the difference in fixations directed to "easy" and "hard" agents was again larger in "hard" events than in "easy" events. As there was no three-way interaction with Time bin, this difference persisted across the entire time window.

Individual interactions of Agent and Event codability with Time bin showed that the rise in fixations to the agent after $400 \mathrm{~ms}$ depended both on properties of the agents and of the events. The interaction of Agent codability with Time bin shows that the difference in fixations to the "easy" and "hard" agents increased over time. As in Experiment 1, the interaction of Event codability with Time bin shows that speakers directed their gaze to the subject character more rapidly in "easy" events than "hard" events.

Fixations between 1000 and $2200 \mathrm{~ms}$. Speakers began looking away from the agent approximately $1000 \mathrm{~ms}$ after picture onset and switched their gaze to the patient approximately $1 \mathrm{~s}$ later (around speech onset). At 1000-1200 ms, speakers were generally less likely to fixate "easy" agents than "hard" agents, and more likely to fixate agents in "easy" events than "hard" events; the two factors interacted in the by-participant analysis (Table 5c).

There was no three-way interaction with Time bin, indicating that this difference persisted across the entire time window. As a result, speakers also shifted their gaze to the patient most quickly in "easy" events with "easy" agents. Importantly, the strongest predictor of the timing of the gaze shift from agents to patients was Event codability: speakers looked to the patient earlier in "easier" events than "harder" events (an interaction of Event codability with Time bin). Consistent with hierarchical incrementality, this result suggests that speakers were able to begin adding the second character to the sentence earlier in items where the event gist was easier to encode. 
3.2.4.2. Effects of Agent codability and Structural priming. Fixations between 0 and $400 \mathrm{~ms}$. Fig. 4c and d shows the timecourse of formulation for items with "easier" and "harder" agents across Prime conditions. Again, speakers were more likely to fixate "easy" agents than "harder" agents across the entire time window: the effect of Agent codability was reliable in the $0-200 \mathrm{~ms}$ time bin (main effect of Agent codability in Table 6a) and was somewhat larger in the $200-400 \mathrm{~ms}$ time bin (an interaction of Agent codability with Time was observed in the by-item analysis).

As predicted by hierarchical incrementality, early fixations to the agent were influenced by structural priming. Speakers directed fewer fixations to the agent after active primes than after other primes at 0-200 ms (neutral and passive primes; the first contrast for Prime condition in Table 6a); there was no interaction with Time bin, indicating that this difference persisted into the 200$400 \mathrm{~ms}$ time bin. The distribution of agent-directed fixations did not differ after neutral and passive primes (the second contrast for Prime condition). The priming effect also did not vary systematically with properties of the agent (no interaction with Agent codability).

Fixations between 400 and 1000 ms. Having shifted their attention away from "easy" agents by $400 \mathrm{~ms}$, speakers were less likely to fixate "easy" agents than "hard" agents at 400-600 ms (a main effect of Agent codability; Table 6b). Fixations to "easy" agents subsequently also rose less steeply than fixations to "hard" agents (an interaction of Agent codability with Time bin).

Importantly, the probability of fixating the agent was higher after active primes and passive primes than neutral primes at $400-600 \mathrm{~ms}$ (the first contrast for Prime condition), and this difference

Table 6

Results of regressions comparing fixations to the agent in active sentences with "easy" and "hard" agents across Prime conditions in Experiment 2.

\begin{tabular}{|c|c|c|c|c|c|c|}
\hline \multirow[t]{2}{*}{ Effect } & \multicolumn{3}{|c|}{ By-participants } & \multicolumn{3}{|l|}{ By-items } \\
\hline & Est. & SE & $t$-Value & Est. & SE & $t$-Value \\
\hline \multicolumn{7}{|l|}{ (a) $0-400 \mathrm{~ms}$} \\
\hline Intercept & -1.78 & .04 & $-48.58^{*}$ & -2.01 & .02 & $-94.38^{*}$ \\
\hline Time bin & $10.08(s)$ & .22 & $45.59^{*}$ & $11.11(\mathrm{~s})$ & .17 & $66.06^{*}$ \\
\hline Agent codability & -.26 & .04 & $-7.36^{*}$ & -.09 & .02 & $-4.06^{*}$ \\
\hline Prime condition: active primes vs. other primes & .20 & .04 & $5.54^{*}$ & $.30(\mathrm{~s})$ & .02 & $18.39^{*}$ \\
\hline Prime condition: neutral primes vs. passive primes & .05 & .04 & 1.20 & $.01(\mathrm{~s})$ & .02 & .33 \\
\hline Time bin $*$ Agent codability & - & - & - & -2.09 & .16 & $-12.91^{*}$ \\
\hline \multicolumn{7}{|l|}{ (b) $400-1000 \mathrm{~ms}$} \\
\hline Intercept & -.13 & .02 & $-6.84^{*}$ & -.32 & .03 & $-10.09^{*}$ \\
\hline Time bin & $1.66(\mathrm{~s})$ & .08 & $20.61^{*}$ & $2.81(\mathrm{~s})$ & .07 & $39.00^{*}$ \\
\hline Agent codability & .22 & .03 & $6.38^{*}$ & .11 & .03 & $3.49^{*}$ \\
\hline Prime condition: neutral primes vs. other primes & .02 & .04 & .52 & .07 & .02 & $3.59 *$ \\
\hline Prime condition: active primes vs. passive primes & -.21 & .04 & $-5.07^{*}$ & -.26 & .02 & $-10.99^{*}$ \\
\hline Time bin $*$ Agent codability & 1.03 & .14 & $7.28^{*}$ & .88 & .07 & $11.73^{*}$ \\
\hline Time bin $*$ Prime condition: neutral primes vs. other primes & .75 & .14 & $5.39^{*}$ & .80 & .09 & $9.32^{*}$ \\
\hline Time bin $*$ Prime condition: active primes vs. passive primes & .93 & .16 & $5.63^{*}$ & 1.07 & .10 & $10.52^{*}$ \\
\hline \multicolumn{7}{|l|}{ (c) $1000-2200 \mathrm{~ms}$} \\
\hline Intercept & .56 & .02 & $23.80^{*}$ & .83 & .02 & $41.69^{*}$ \\
\hline Time bin & -.81 & .04 & $-22.10^{*}$ & $-1.08(\mathrm{~s})$ & .02 & $-45.93^{*}$ \\
\hline Agent codability & .30 & .02 & $15.27^{*}$ & .29 & .01 & $19.71^{*}$ \\
\hline Prime condition: active primes vs. other primes & .05 & .02 & $2.71^{*}$ & -.07 & .02 & $-3.83^{*}$ \\
\hline Prime condition: neutral primes vs. passive primes & -.02 & .02 & -.69 & .10 & .02 & 4.69* \\
\hline $\begin{array}{l}\text { Agent codability } * \text { Prime condition: active primes vs. other } \\
\text { primes }\end{array}$ & -.06 & .04 & -1.54 & -.11 & .01 & $-10.95^{*}$ \\
\hline $\begin{array}{l}\text { Agent codability } * \text { Prime condition: neutral primes vs. passive } \\
\text { primes }\end{array}$ & .27 & .05 & $5.48^{*}$ & .14 & .01 & $11.83^{*}$ \\
\hline Time bin $*$ Prime condition: active primes vs. other primes & - & - & - & .37 & .03 & $11.64^{*}$ \\
\hline Time bin $*$ Prime condition: neutral primes vs. passive primes & - & - & - & -.33 & .04 & $-8.74^{*}$ \\
\hline
\end{tabular}

${ }^{\dagger} p<.10$.

* $p<.05$. 
increased over time (the first contrast in the interaction of Prime condition with Time bin), suggesting possible facilitation from exposure to a transitive sentence or a transitive-event conceptual structure. In addition, there were also more fixations to the agent after active primes than passive primes at 400$600 \mathrm{~ms}$ (the second contrast for Prime condition), although fixations to the agent then rose more sharply after passive primes (the second contrast in the interaction of Prime condition with Time bin). The overall pattern is thus different from Experiment 1, where fixations to the agent decreased after agent primes relative to other primes, and shows evidence of guidance from a larger framework during linguistic encoding.

Fixations between 1000 and 2200 ms (speech onset). At 1000-1200 ms, speakers were less more likely to fixate "easy" agents than "hard" agents (a main effect of Agent codability; Table 6c). The rates at which fixations to the agent decreased over time in items with "easy" and "hard" agents did not differ (no interaction of Agent codability with Time bin).

Differences across Prime conditions were observed in this time window as well. The by-participant analysis shows that there were fewer fixations to the agent after active primes than other primes at 1000-1200 ms (the first contrast for Prime condition), and the absence of an interaction with Time bin suggests that this difference persisted across the entire time window. By comparison, the by-item analysis shows a steeper decline in agent-directed fixations after active primes than after other primes (the first contrast in the interaction of Prime condition with Time bin). Together, the two analyses suggest that speakers spent less time fixating agents in structurally primed (active-primed) sentences. A difference between passive primes and neutral primes was observed only in the by-item analysis.

In addition, priming effects were sensitive to properties of the agents. The first contrast in the interaction of Agent codability with Prime condition shows that, at 1000-1200 ms, there were somewhat more fixations to agents after active primes than other primes in items with "hard" agents (the effect reached significance in the by-item analysis). The second contrast in the interaction of Agent codability with Prime condition shows that, at $1000-1200 \mathrm{~ms}$, there were more fixations to agents after passive primes than neutral primes in items with "hard" agents.

3.2.4.3. Effects of Event codability and Structural priming. Fixations between 0 and $400 \mathrm{~ms}$. Fig. 5a and b shows the timecourse of formulation for sentences describing "easy" and "hard" events across Prime conditions. There were more fixations to agents in "hard" events than "easy" events at 0-200 ms; in "easy" events, speakers were less likely to fixate either character preferentially (a main effect of Event codability; Table 7a). Fixations to the agent then increased more quickly in "hard" events than in "easy" events by $400 \mathrm{~ms}$ (producing an interaction of Event codability with Time bin).

Again, speakers directed fewer fixations to the agent after active primes than after neutral and passive primes in the $0-200 \mathrm{~ms}$ time bin (the first contrast for Prime condition), and this effect persisted into the $200-400 \mathrm{~ms}$ time bin (there was no interaction with Time bin). In addition, the reduction in agent-directed fixations with structural priming was larger in "easier" than "harder" events (the first contrast in the interaction between Prime condition and Event codability).

Speakers were also somewhat more likely to fixate agents after passive primes than neutral primes (the second contrast for Prime condition), particularly in "harder" events (the second contrast in the interaction between Prime condition and Event codability).

Fixations between 400 and $1000 \mathrm{~ms}$. At $400-600 \mathrm{~ms}$, speakers were less likely to fixate agents in "easy" events than "hard" events (a main effect of Event codability in the by-participant analysis; Table 7b), but fixations to the agent then rose more quickly in "easy" events than "hard" events (resulting in an interaction between Event codability and Time bin). There were also more agentdirected fixations after active primes and passive primes than after neutral primes at $400-600 \mathrm{~ms}$ (the first contrast for Prime condition), and fixations to the agent rose more quickly in these conditions over time (the first contrast in the interaction of Prime condition with Time bin). Additionally, speakers were more likely to fixate the agent after active primes than passive primes at $400-600 \mathrm{~ms}$, but fixations to the agent then increased more quickly after passive primes than after active primes (the second contrast in the interaction of Prime condition with Time bin).

Fixations between 1000 and $2200 \mathrm{~ms}$ (speech onset). At 1000-1200 ms, speakers were somewhat less likely to fixate the agent in "easy" events than "hard" events (a main effect of Event codability in the by-participant analysis; Table 7c). There was no interaction with Time in the by-participant analysis, 
(a) "EASY" EVENTS

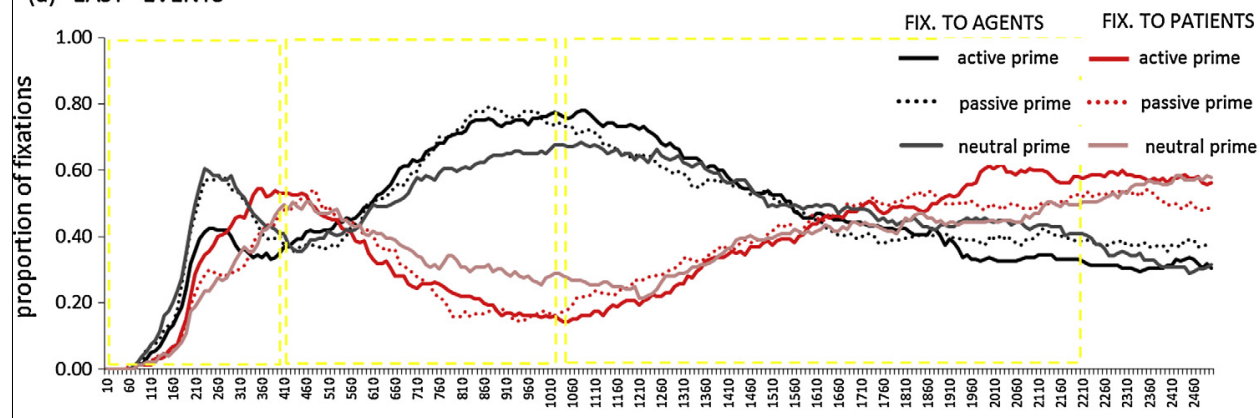

(b) "HARD" EVENTS

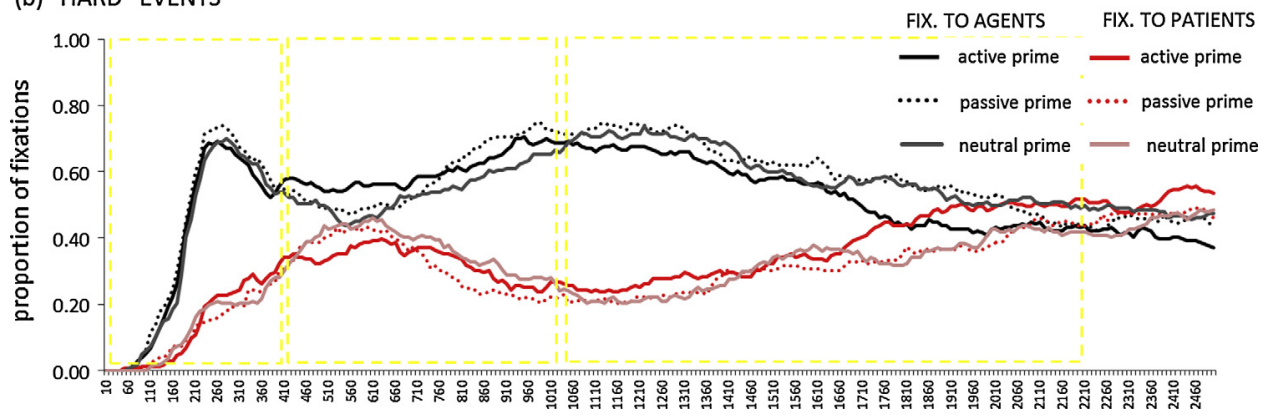

Fig. 5. Timecourse of formulation for active sentences in Experiment 2 with respect to Event codability ("easy" vs. "hard" events) and Prime condition.

suggesting that this difference persisted across the entire time window and resulted in an earlier shift of gaze to the patient in "easy" events than "hard" events. This interaction was reliable in the by-item analysis, indicating that the decline in agent-directed fixations after $1000 \mathrm{~ms}$ was faster in "easy" events than in "hard" events. Together, the two analyses show that speakers fixated agents for less time when the gist of the event was easy to encode than when it was harder to encode.

Finally, speakers were less likely to look at the agent after active primes than after other primes at 1000-1200 ms (the first contrast for Prime condition) and then shifted their gaze to the patient earlier after active primes (the first contrast in the interaction of Prime condition with Time bin). They were also somewhat more likely to shift their gaze to the patient earlier after neutral primes than passive primes (the second contrast in the interaction of Prime condition with Time bin).

\subsection{Discussion}

Experiment 2 showed effects of non-relational and relational variables on both sentence form and sentence formulation that were similar to those used in Experiment 1. With respect to sentence form, the results showed the expected robust effects of character accessibility and structural priming. Properties of agents were again strong predictors of sentence form, consistent with linear incrementality. The structural priming manipulation showed that sentence form was also influenced by changes in the ease of deploying abstract structure-building procedures, and again, the primes differed in their priming ability: speakers produced a comparable number of active sentences after active primes and neutral primes, whereas only passive primes reliably reduced production of actives. Effects of the active primes were limited to items with "harder" agents, or items where properties of the agent favored selection of a passive structure rather than the preferred active structure. Thus as in Experiment 1, 


\section{Table 7}

Results of regressions comparing fixations to the agent in active sentences describing "easier" and "harder" events across Prime conditions in Experiment 2.

\begin{tabular}{|c|c|c|c|c|c|c|}
\hline \multirow[t]{2}{*}{ Effect } & \multicolumn{3}{|c|}{ By-participants } & \multicolumn{3}{|l|}{ By-items } \\
\hline & Est. & SE & $t$-Value & Est. & SE & $t$-Value \\
\hline \multicolumn{7}{|l|}{ (a) $0-400 \mathrm{~ms}$} \\
\hline Intercept & -1.76 & .04 & $-48.61^{*}$ & -2.01 & .02 & $-102.14^{*}$ \\
\hline Time bin & $9.77(\mathrm{~s})$ & .21 & $45.88^{*}$ & $11.11(\mathrm{~s})$ & .18 & $63.44^{*}$ \\
\hline Event codability & .38 & .03 & $12.14^{*}$ & .20 & .03 & $8.88^{*}$ \\
\hline Prime condition: active primes vs. other primes & .19 & .03 & $5.73^{*}$ & .28 & .02 & $16.85^{*}$ \\
\hline Prime condition: neutral primes vs. passive primes & .05 & .04 & 1.38 & .04 & .02 & $1.94^{*}$ \\
\hline $\begin{array}{l}\text { Event codability } * \text { Prime condition: active primes vs. other } \\
\text { primes }\end{array}$ & -.46 & .07 & $-6.93^{*}$ & -.21 & .02 & $-10.76^{*}$ (a) \\
\hline $\begin{array}{l}\text { Event codability } * \text { Prime condition: neutral primes vs. } \\
\quad \text { passive primes }\end{array}$ & .26 & .08 & $3.36^{*}$ & .10 & .02 & $4.38^{*}(\mathrm{a})$ \\
\hline \multicolumn{7}{|l|}{ (b) $400-1000 \mathrm{~ms}$} \\
\hline Intercept & -.10 & .02 & $-5.72^{*}$ & -.32 & .03 & $-9.68^{*}$ \\
\hline Time bin & 1.33 & .07 & $19.41^{*}$ & $2.76(\mathrm{~s})$ & .08 & $34.88^{*}$ \\
\hline Event codability & .11 & .03 & $3.25^{*}$ & .01 & .04 & .23 \\
\hline Prime condition: neutral primes vs. other primes & .10 & .04 & $2.93^{*}$ & .07 & .02 & $3.43^{*}$ \\
\hline Prime condition: active primes vs. passive primes & -.20 & .04 & $-4.92^{*}$ & -.26 & .02 & $-11.11^{*}$ \\
\hline Time bin $*$ Event codability & -.74 & .14 & $-5.41^{*}$ & -.32 & .10 & $-3.32 *(a)$ \\
\hline Time bin $*$ Prime condition: neutral primes vs. other primes & .46 & .14 & $3.15^{*}$ & .86 & .09 & $9.87^{*}$ \\
\hline Time bin $*$ Prime condition: active primes vs. passive primes & .73 & .17 & $4.37^{*}$ & 1.07 & .10 & $10.37^{*}$ \\
\hline \multicolumn{7}{|l|}{ (c) $1000-2200 \mathrm{~ms}$} \\
\hline Intercept & .55 & .03 & $21.98^{*}$ & .85 & .02 & $39.77^{*}$ \\
\hline Time bin & $-.80(\mathrm{~s})$ & .04 & $-20.53^{*}$ & $-1.08(\mathrm{~s})$ & .02 & $-47.41^{*}$ \\
\hline Event codability & .17 & .02 & $8.76^{*}$ & -.03 & .03 & -1.25 \\
\hline Prime condition: active primes vs. other primes & -.08 & .04 & $-2.17^{*}$ & -.05 & .02 & $-3.01^{*}$ \\
\hline Prime condition: neutral primes vs. passive primes & .01 & .04 & .32 & .07 & .02 & $3.27^{*}$ \\
\hline Time bin $*$ Event codability & - & - & - & .31 & .03 & $10.97^{*}$ \\
\hline Time bin $*$ Prime condition: active primes vs. other primes & .30 & .06 & $4.70^{*}(\mathrm{a})$ & .38 & .03 & $11.62^{*}$ \\
\hline $\begin{array}{l}\text { Time bin } * \text { Prime condition: neutral primes vs. passive } \\
\text { primes }\end{array}$ & -.14 & .08 & $-1.79^{\dagger}$ & -.31 & .04 & $-8.31^{*}$ \\
\hline
\end{tabular}

${ }^{*} p<.05$.

$+p<.10$.

the asymmetry in priming effects is consistent with earlier observations that generation of a frequent structure is influenced by priming to a lesser degree than generation of an infrequent structure.

More importantly, the timecourse of formulation again showed sensitivity to the ease of encoding non-relational and relational information. First, the analysis of first fixations showed that the degree to which speakers began sentences with the first-fixated character depended on higher-level factors. The suitability of a character for subjecthood depended on the ease of encoding the event and the ease of constructing a suitable sentence structure: first-fixated characters were less likely to become subjects in "easier" events than "harder" events and in structurally primed sentences than unprimed sentences. Thus overall, the influence of visual information on selection of a starting point was relatively weak: although speakers may begin sentences with the first-fixated character in subject position (Experiment 1, linear incrementality), sentence form is also the product of more complex interactions between lower-level perceptual factors and higher-level relational factors (Experiment 2, hierarchical incrementality).

Second, timecourse analyses showed a strong influence of variables influencing encoding of relational information and a weaker effect of variables influencing encoding of non-relational information. Effects of Event and Agent codability (Table 5) were comparable to those in Experiment 1 (Table 3), as the two experiments used similar items. During early formulation (0-400 ms), Event codability produced effects consistent with hierarchically incremental planning, and, importantly, constrained the effect of Agent codability. When describing higher-codability events, speakers showed only a small 
preference for the agent over the patient, and properties of the agent were weak predictors of the magnitude of this preference. In lower-codability events, on the other hand, the pattern of early fixations was primarily determined by Agent codability: speakers shifted their attention very rapidly to "easy" agents and away from "hard" agents. As in Experiment 1, this result suggests that speakers attempted to select a starting point based on character accessibility when they could not easily select a starting point based on their construal of the gist of the event. It also extends Kuchinsky and Bock's (2010) observations about the influence of relational factors on selection of starting points to the timecourse of sentence formulation.

The benefits of early encoding of event gist carried over to later time windows as well. In highercodability events, speakers directed their attention to the agent relatively quickly after $400 \mathrm{~ms}$. By comparison, the strong preference to fixate the agent in lower-codability events before $400 \mathrm{~ms}$ resulted in a less consistent pattern of fixations: rapid shifts of attention to the agent within $400 \mathrm{~ms}$ of picture onset were followed by an extended time window where speakers fixated the patient (as in Experiment 1, large shifts of attention from one character to another suggest that the two characters were encoded sequentially). As a result, agent-directed fixations after $400 \mathrm{~ms}$ also showed a joint influence of Event and Agent codability: speakers were able to deploy their attention to the agent and finally shift their gaze to the patient earlier in "easier" events than in "harder" events (this effect was stronger than in Experiment 1, which showed a main effect of Event codability but no interaction of Event codability with Time bin).

Critically, the effect of structural primes on formulation was different from the effect of lexical primes in Experiment 1: the structural primes produced shifts in planning patterns that resembled the effect of Event codability on formulation and thus were consistent with hierarchical incrementality. As predicted, active primes reduced the proportion of agent-directed fixations within $400 \mathrm{~ms}$ of picture onset in active sentences, suggesting a very early effect of structural processes on visual inspection of an event. The interaction with Event codability in this time window indicates stronger facilitation of early relational encoding when both conceptual and linguistic structures were easy to generate. After active primes, speakers also quickly directed their gaze to the agent after $400 \mathrm{~ms}$ and to the patient before speech onset. Thus differences across prime conditions show a difference in the way speakers initiated the formulation process $(0-400 \mathrm{~ms})$ and then proceeded to encode the two characters linguistically (after $400 \mathrm{~ms}$ ) with and without structural support.

\section{General discussion}

\subsection{Summary}

In two experiments, speakers described "easy" and "hard" events with "easy" and "hard" characters after receiving lexical primes (Experiment 1) or structural primes (Experiment 2). Variables known to influence sentence form produced the expected effects in both experiments. On the one hand, strong effects of character codability, as well as experimentally manipulated character name accessibility in Experiment 1, confirm that speakers prefer to encode accessible characters first and thus build structures that accomodate placement of these characters in subject position (e.g., Altmann \& Kemper, 2006; Bock, 1986b; Ferreira, 1994; Gleitman et al., 2007; Prat-Sala \& Branigan, 2000). On the other hand, strong effects of event codability in both experiments, as well as experimentally manipulated ease of structural assembly in Experiment 2, show that conceptual processes and abstract structural processes attenuate effects of character codability on sentence form. The two sets of results, obtained with similar sets of items, show the influence of two different processes on the generation of a sentence structure: one illustrates lexical guidance and the other illustrates the influence of relational processes.

These effects originated in different types of incremental planning. Analyses of eye-movements across a range of time windows consistently revealed a direct link between the ease of executing non-relational and relational processes and the way that speakers prepared and assembled different sentence increments. First, first-fixated characters tended to become sentence subjects but the ease of gist encoding and structural assembly reduced the impact of first fixations on sentence form: 
first-fixated characters were less likely to become subjects with structural support. Second, the distribution of fixations to the two characters within $400 \mathrm{~ms}$ of picture onset also showed opposite effects of non-relational and relational variables. The ease of encoding individual characters predicted the likelihood of speakers preferentially fixating one character over the other character, suggesting fast encoding of non-relational information at the outset of formulation. In contrast, the ease of encoding the conceptual structure of an event and assemblying an abstract syntactic structure determined the extent to which speakers distributed their gaze between two characters more equally, suggesting immediate sensitivity to relational information as well.

Differences in formulation across items and conditions were also observed between $400 \mathrm{~ms}$ and the point of gaze shifts to the second character. Overall, fast deployment of gaze to a subject character at the outset of formulation ( $0-400 \mathrm{~ms}$ ) was followed by a shift of gaze away from this character at $400 \mathrm{~ms}$ (indicating sequential, character-by-character encoding), while distributing attention between two characters at the outset of formulation $(0-400 \mathrm{~ms})$ was followed by faster gaze shifts to the subject character after $400 \mathrm{~ms}$. The former was observed in events with "easy" agents and in events with lexically primed agents; the latter was observed in "easy" events and in events that were structurally primed. At speech onset, gaze shifts from the agent to the patient followed from the distribution of fixations seen in earlier windows and were thus also predicted by properties of the events, properties of the agents, and by the lexical and structural primes.

In all comparisons, the two variables that were not manipulated experimentally (event and character codability) and the two variables that were experimentally controlled (ease of lexical and structural encoding in Experiments 1 and 2) produced similar results. Similarity of these effects does not equate the precise mechanisms underlying conceptual and linguistic encoding, but it confirms that processing differences relevant for formulation are between the class of processes that influence encoding of discrete, non-relational pieces of information (individual characters) and the class of processes that influence encoding of relationships between characters. Thus in the transition from thought to speech, variability in formulation can be traced back to the encoding of two qualitatively different types of information, and specifically, to the speed with which these encoding operations can be completed (also see Konopka, 2012).

\subsection{Flexibility in incremental message and sentence formulation}

The combined effects of non-relational and relational variables as well as speakers' sensitivity to the ease of carrying out these processes suggests that, while these variables systematically influence formulation, production may be neither strictly linearly incremental nor strictly hierarchically incremental. Indeed, the findings of Experiment 1 and 2 are more consistent with weaker versions of both linear and hierarchical incrementality rather than with a deterministic, inflexible planning process. For example, with respect to selection of sentence structure, speakes may select first-fixated characters as starting points, but preferential encoding of agents over patients suggests that the assignment of characters to the subject slot also depends on relational biases. Similarly, accessible characters are more likely to become subjects than less accessible characters, but these effects also depend on the influence of relational variables. With respect to the timecourse of formulation, non-relational and relational variables jointly influenced the early distribution of fixations to event characters and the timing of gaze shifts from one character to another. For example, early shifts of gaze to accessible agents in active sentences $(0-200 \mathrm{~ms})$ showed an early effect of non-relational variables, but rapid shifts of gaze to patients by $400 \mathrm{~ms}$ showed that speakers do not necessarily continue encoding that character preferentially before speech onset. Evidence for one form of planning being preferred over the other was only obtained in two timecourse analyses: event codability largely determined the distribution of early agent-directed fixations in Experiments 1 and 2, with speakers falling back on linear incrementality only when relational encoding was harder to complete.

Overall, the results support the proposal of a continuum of incremental planning that permits shifts in planning strategies from sentence to sentence. The two experimental manipulations highlighted these shifts directly: lexical priming in Experiment 1 produced a shift to the linear end point of the continuum (Gleitman et al., 2007), while structural priming in Experiment 2 produced a shift to the hierarchical end point of this continuum (Bock et al., 2004; Kuchinsky \& Bock, 2010; Kuchinsky 
et al., 2011). In sum, the production system allows for the order of encoding operations to be flexible: production may begin both with encoding of single characters and with the formulation of a "thought" or idea - something akin to a proposition - in different contexts.

Comparing across experiments, the principle behind this flexibility appears to be a general preference for completing easier processes before harder processes. This resembles Levelt's (1989) minimal load principle at the discourse level (also see Ferreira \& Henderson, 1998): completing easy processes before hard processes lightens the load on the production system and enables speakers to quickly begin and complete encoding of individual increments. For example, reliance on activation patterns of individual words to select a starting point can be beneficial in so far as it allows speakers to produce accessible words first and quickly shift processing resources to the next increment (Ferreira \& Swets, 2002; also see Ferreira, 1996). In contrast, prioritizing encoding of relational information can be beneficial in so far as a larger message framework can provide top-down guidance to rapidly bind individual increments of a sentence (e.g., individual words) into a full utterance. Given that the processing demands of production in every-day situations can change from context to context (as they did in these experiments), minimizing processing load may be a ubiquitous planning strategy. Earlier work suggested that flexibility can benefit speed as well as fluency of speech (e.g., Ferreira \& Swets, 2002; Levelt, 1989; Wagner et al., 2010), so the specific balance between linearly and hierarchically incremental planning may reflect rapid (and implicit) weighing of the different advantages conferred by these planning strategies in each production context separately.

\subsection{Relationship between message-level and sentence-level structures}

Sensitivity to differences in ease of encoding during formulation bears on two questions relevant for most production models: questions about the representation of conceptual and linguistic structures and thus questions about information flow in the production system. Similarity in the effects of event codability and of the ease of structural assembly on formulation points to a tight temporal link between the encoding of a relational, prelinguistic structure and its linguistic counterpart. Debates about structural processing in production often concern the abstractness of syntactic structures (or syntactic plans; see Pickering \& Ferreira, 2008, for a review), so the direction of these effects can help distinguish between functional and abstract structural accounts of syntactic encoding.

These debates have so far been addressed in structural priming studies by testing the extent to which repetition of structure from one sentence to another can be explained solely by priming of conceptual-relational information (a functionalist perspective) and the extent to which structurebuilding procedures are independent of conceptual pressures (an abstract structural perspective; see Bock, 1982; Bock, Loebell, \& Morey, 1992, for reviews). In principle, a sentence structure can be the product of mapping operations that bind individual elements of a message representation (e.g., characters in an event) to thematic roles (agents and patients) or it can be generated by structural procedures that are less sensitive to the identity of the characters filling those roles.

Examining the effects of structural primes on the timecourse of sentence formulation offers a new approach to testing the nature of the dependencies between conceptual and linguistic structural processes. Functional accounts of syntax predict that the effect of structural primes should be limited to priming of thematic roles: an active prime should bias assignment of the agent to subject position and a passive prime should bias assignment of the patient to subject position (a form of prominence priming; see Pickering \& Ferreira, 2008). On this account, speakers in Experiment 2 should have quickly fixated and encoded the agent in the pictured event after hearing an active prime, and should have quickly fixated and encoded the patient after hearing a passive prime. This outcome would have resembled accessibility effects obtained in Experiment 1 with lexical primes, supporting linear rather than hierarchical incrementality (but see Chang, Bock, \& Goldberg, 2003, for priming of thematic roles in a different structural alternation). Instead, structural priming in Experiment 2 favored encoding of information about both characters in the event immediately after picture onset. The results show that structural procedures are concerned with expressing relational information rather than facilitating the assignment of a particular character to a particular structural slot, and is thus inconsistent with functional accounts of syntax. 
Importantly, early effects of linguistic structure on formulation suggest an influence of linguistic processes on representations generated at the interface of message and sentence planning. A related question then is whether variables influencing encoding of linguistic relational information can also influence message content (or speakers' perspective on an event). Recent work by Bunger, Papafragou, and Trueswell (in press) suggests that high similarity in the relational content of some conceptual representations and linguistic structures may indeed change what speakers express about an event after exposure to structural primes. There is little evidence to suggest that this might have been the case in the two experiments in this paper: the lexical primes in Experiment 1 and the structural primes in Experiment 2 did not impact the heterogeneity of nouns and verbs chosen to refer to the two characters or to describe the relationships between them. ${ }^{7}$ Thus overall, there is stronger evidence that primes shaped the way that the different increments of a message and sentence were assembled rather than influencing what speakers said.

A compelling test of conceptual-linguistic priming is also afforded by cross-linguistic comparisons of formulation. One long-standing, attractive hypothesis in the field is that differences in phrasal syntax across languages may support different patterns of incremental planning by requiring speakers to encode some types of information before others. Cross-linguistic studies therefore provide unique insight into possible effects of linguistic structure on early sentence formulation and can help to identify limits in the flexibility of production processes (Brown-Schmidt \& Konopka, 2008; Christianson \& Ferreira, 2005; Myachykov, Garrod, \& Scheepers, 2009; Norcliffe, Konopka, Brown, \& Levinson, 2013; Sauppe, Norcliffe, Konopka, van Valin, \& Levinson, 2013).

\subsection{Generalization to other types of messages}

In our experiments, the non-relational and relational variables were uncorrelated. Namely, Event codability was not correlated with either Agent or Patient codability, and the content words selected to refer to the two characters had no subcategorization preferences that either favored or disfavored selection of active or passive syntax. In principle, however, properties of individual characters and properties of events in normal production can operate independently as well as in concert to influence the timecourse of formulation. For example, speakers' choice of referential terms for individual characters may depend on their role in the event: selecting labels such as teacher and student for two characters is contingent on apprehension of the event structure. Identification of a character as a member of a particular profession can also influence the interpretation of the action performed by this character: e.g., verbs like shouting and directing may be better suited for sports fans and coaches rather than the other way around.

To test for interactions between these variables, it is important to first specify the level at which interdependence between non-relational and relational information may be observed. This requires clarifying the sub-components of processes like event apprehension (or encoding of event gist), i.e., explaining how speakers integrate various pieces of information about an event to create a representation of its relational structure within the time it takes to process visual information during one or two fixations. On the one hand, research in memory and visual cognition has shown that people can identify characters more quickly and accurately in coherent scenes than incoherent scenes (see Henderson \& Ferreira, 2004, for a review), supporting the idea of fast integration of non-relational and relational information during construction of an event representation. On the other hand, encoding of event gist is more poorly defined in psycholinguistic work. For example, on Griffin and Bock' (2000) account, apprehension involves encoding enough information to specify the relationship between two characters (chasing, kicking, etc.) and begin linguistic encoding, while on other accounts (e.g., Bunger et al., in press), identification of an event class (e.g., identifying an event as a motion event) can also constitute encoding of event gist.

\footnotetext{
${ }^{7}$ Effects of primes on sentence content were only observed in Experiment 2 with passive sentences: here, passive primes increased rates of production of full passives and decreased rates of production of truncated passives. It is debatable, however, to what extent expressing the agent in a passive sentence implies formulation of a different "message" than for a sentence where the agent is omitted.
} 
Minimally, developing detailed models of event apprehension requires understanding how relational information contributes to encoding of the non-relational content of an event, and vice versa. Hafri et al. (2012) recently showed that speakers can extract basic information about event structure in less than $100 \mathrm{~ms}$ from perceptual features of individual characters that are typically associated with "agenthood" (also see Bock et al., 2003; Dobel et al., 2007; Potter, 1976). Given the speed with which speakers can link visual information to event categories, the two experiments in this paper suggest that processing occurring within the first $400 \mathrm{~ms}$ of picture onset must be a multi-faceted process. Indeed, speakers did not fixate and continue fixating the character produced in subject position from picture onset until speech onset: plotting the timecourse of agent-directed fixations in active sentences showed that, on average, speakers first fixated the agent and then the patient before $400 \mathrm{~ms}$. Since it is possible to encode coarse-grained information about the event during initial fixations to the agent, this pattern suggests that fixating the second character served an additional purpose before speakers redirected their gaze to the agent (the first-mentioned character). The time window argued to correspond to event apprehension by Griffin and Bock (2000) may thus encompass encoding of coarse-grained as well as finer-grained conceptual properties of an event; the extent to which these processes draw on non-relational and relational information remains to be determined.

\subsection{Conclusion}

The timecourse of message formulation and sentence formulation can vary systematically from context to context. Differences in the nature of the messages that speakers intend to communicate as well as moment-to-moment fluctuations in the speed of performing the necessary encoding operations can create a bias for encoding either relational or non-relational information with priority. Flexibility in the production system allows speakers to begin formulation by prioritizing encoding of information that is easy to process, and implicit choices of planning strategies have consequences for the timecourse of formulation from the generation of a message until articulation.

Of course, flexibility may be the rule rather than the exception for production outside of the lab as real-life production contexts are undoubtably richer than in laboratory tasks. However, there must also be bounds on this flexibility. At the extreme, radical linear incrementality is unlikely to account for formulation of sentences with a complex conceptual structure because some form of conceptual guidance is necessary for speakers to structure sentences around the "thought" that they want to communicate. Hierarchical incrementality is also unlikely to mediate construction of simpler phrases (e.g., conjuncts), where word order may reflect differences in the order of word activation (axe and saw or saw and axe) or common usage (king and queen but not queen and king). Thus as in studies examining context effects on various aspects of on-line processing (e.g., use of common ground in conversational exchanges; Brown-Schmidt \& Konopka, 2011), an emphasis on flexibility requires further specification of how and when different variables shape formulation.

\section{Author note}

These experiments were first presented at the 18th meeting of the AMLaP conference in 2011. We thank Moniek Schaars for invaluable help with data collection and processing, and Katrien Scheibe and Samantha Hoogen for assistance with data collection.

\section{Appendix A}

Target events presented in Experiment 1 (the agent, patient, and unrelated prime sentences in Dutch and English respectively are listed in parentheses). 
1. Bulldozer tearing down building

(De machine is lawaaiig / Het paleis staat op de top van de berg / De balletdansers dansen)

(The machine is noisy / The palace is at the top of the hill / The ballet dancers are dancing)

2. Tree crushing man

(Het hout is klaar om vervoert te worden / De wandelaar is aan het klimmen / De olifant drinkt)

(The wood is ready to be shipped / The hiker is climbing / The elephant is drinking)

3. Bee stinging man

(De honing is in de aanbieding / De opa is aan het lezen / De robot loopt)

(The honey is on sale / The grandfather is reading / The robot is walking)

4. Man shooting woman

(De tiener rolschaatst / Het meisje slaapt / De bloemen zijn verwelkt)

(The teenager is rollerskating / The girl is sleeping / The flowers are wilting)

5. Baseball hitting boy

(De shuttle ligt in het gras / De man ligt in de hangmat / De telefoon rinkelt)

(The shuttle is lying in the grass / The man is lying in a hammock / The phone is ringing)

6. Dog chasing mailman

(De wolf huilt naar de maan / De verkoper wacht buiten / De paraplu waait weg)

(The wolf is howling at the moon / The salesman is waiting outside / The umbrella is flying away)

7. Journalist interviewing actor

(De schrijver denkt / De muzikant buigt / Het hert verstopt zich achter de struik)

(The writer is thinking / The musician is bowing / The deer is hiding behind a bush)

8. Boxer hitting cheerleader

(De gladiator rust uit / De fans juichen / Het zaad komt uit)

(The gladiator is resting / The fans are cheering / The seed is sprouting)

9. Snake scaring girl

(De hagedis zit op een steen / Het kind is aan het schommelen / De bal rolt van de berg)

(The lizard is sitting on a stone / The child is swinging / The ball is rolling down the hill)

10. Masseuse massaging man

(De kapper werkt / De jongen niest / De hut staat in brand)

(The hairdresser is working / The boy is sneezing / The hut is burning)

11. Shark swallowing swimmer

(De goudvis zwemt in de kom / De duikbril hangt aan de hak / De wieltjes draaien)

(The goldfish is swimming in a bowl / The goggles are hanging on a hook / The wheels are turning)

12. Photographer filming model

(De schilder is aan het werk / De paspoppen staan in de hoek / De eieren bakken in de koekenpan)

(The painter is working / The mannequins are standing in the corner / The eggs are frying)

13. Policeman stopping driver

(De detective is aan het roken / De fietser rijdt een heuvel op / De vlinder zit op een bord)

(The detective is smoking / The biker is riding up the hill / The butterfly is sitting on a plate)

14. Lighting striking church

(De regen valt neer / De oude bel luidt / Het konijn komt uit de hoed)

(The rain is pouring down / The old bell is ringing / The rabbit is coming out of the hat)

15. Policeman arresting man

(De bewaker staat bij het hek / De jongen rilt / De vulkaan barst uit)

(The guard is standing by the gate / The boy is shivering / The volcano is erupting)

16. Bomb hitting ship

(Het pistool ligt in de lade / De kano's liggen op het strand / De farao zwaait)

(The gun is lying in the drawer / The canoes are lying on the beach / The pharaoh is waving)

17. Fireman saving child

(De soldaat sloopt over de balk / De baby kruipt / De beer gromt)

(The soldier is walking on a log / The baby is crawling / The bear is growling)

18. Bird pulling worm out of the ground

(De pinguin schaatst / De kever zit in de pot / De serveerster struikelt)

(The penguin is skating / The beetle is sitting in a jar / The waitress tripped)

19. Army attacking castle

(De tank is aan het schieten / De muur brokkelt af / Het water kookt in de ketel)

(The tank is firing / The wall is crumbling / The water is boiling in the kettle)

20. Alarm waking up boy

(De luidspreker staat op de venster bank / Het meisje is touwtje aan het springen / Het hek staat open)

(The loudspeaker is standing on the windowsill / The girl is skipping rope / The gate is open)

21. Horse kicking cow

(Het zadel hangt op het hek / De melkfles staat bij de deur / De gevangene zit achter de tralies)

(The saddle is hanging on the fence / The bottle of milk is at the door / The prisoner is sitting behind bars) 
22. Judge giving tennis player a medal

(De scheidsrechter wijst / De hardloper rekt zijn spieren / De vaas valt van de tafel)

(The referee is pointing / The runner is stretching / The vase is falling off the table)

23. Thief stealing painting

(De spion is aan het gluren / Het beeld staat in een doos / De ballon knapt)

(The spy is spying / The statue is standing in a box / The balloon is bursting)

24. Ambulance hitting woman

(Het ziekenhuisbed is leeg / Het dienstmeisje is aan het stofzuigen / De ventilator staat aan)

(The hospital bed is empty / The maid is vacuuming / The fan is turned on)

25. Bishop crowning king

(De monnik is aan het bidden / De president spreekt / De sneeuwpop smelt)

(The monk is praying / The president is speaking / The snowman is melting)

26. Helicopter pulling diver out of the water

(Het vliegtuig vertrekt / De matroos drinkt / De pannen hangen in een rij)

(The airplane is taking off / The sailor is drinking / The pots are hanging in a row)

27. Sprinkler splashing old woman

(De gieter lekt / De heks zit op een bezem stil / De $c d$ is gebroken)

(The watering can is leaking / The witch is riding on a broom / The $c d$ is broken)

28. Truck towing car

(De sneeuwschuiver wacht voor het stoplicht / De motorfiets staat tegen de lantaarnpaal / De dwerg lacht)

(The snowplow is standing at the stoplight / The motorcycle is leaning against the lamp post / The dwarf is laughing)

29. Cat catching mouse

(De tijger springt door een hoepel / De kaas ligt in de koelkast / De man is zich aan het scheren)

(The tiger is jumping through a hoop / The cheese is in the fridge / The man is shaving)

30. Nurse vaccinating patient

(De chirurg is moe / Het slachtoffer is bewusteloos / De kleren drogen aan de waslijn)

(The surgeon is tired / The victim is unconscious / The clothes are drying on a line)

\section{Appendix B}

Targets events presented in Experiment 2 (the transitive and intransitive prime sentences in Dutch and English are listed in parentheses).

1. Bulldozer tearing down building

(De alien trekt de astronaut mee / Twee mensen roeien)

(The alien is pulling the astronaut / Two people are rowing)

2. Thief stealing painting

(De professor feliciteert de student / /De eieren bakken in de koekenpan)

(The professor is congratulating the student / The eggs are frying in the pan)

3. Bee stinging man

(De steen heeft het raam gebroken/ De kleren drogen)

(The rock is breaking the window / The clothes are drying)

4. Man shooting woman

(De ooievaar brengt de baby / De bloemen zijn verwelkt)

(The stork is bringing the baby / The flowers are wilting)

5. Robot smashing computer

(Het dienstmeisje gooit het vuilnis weg / Twee mensen trouwen)

(The maid is throwing out the garbage / Two people are getting married)

6. Dog chasing mailman

(De technicus maakt de tv / Enkele munten vallen uit een zak)

(The technician is fixing the tv / The coins are falling out of the bag)

7. Journalist interviewing actor

(De kikker vangt de vlieg / De beer en de pinguin dansen)

(The frog is catching the fly / The bear and the penguin are dancing)

8. Boxer hitting cheerleader

(De moeder kleedt de jongen aan / De monniken bidden)

(The mother is dressing the boy / Two monks are praying)

9. Snake scaring girl

(De coach omhelst de tennister / De kaas en de wijn zijn in de aanbieding)

(The coach is hugging the tennis player / The cheese and the wine are on sale)

10. Masseuse massaging man 
(De eendjes volgen moeder eend/ De herten verstoppen zich achter de struiken)

(The ducklings are following the mother duck / The deer are hiding behind the bushes)

11. Shark swallowing man

(De Nederlandse speler maakt een doelpunt / De bellen luiden)

(The Dutch player is scoring a goal / The bells are ringing)

12. Camera man filming model

(De trein verplettert de bus / De olievaten lekken)

(The train is crushing the bus / The oil cans are leaking)

13. Policeman stopping car

(De leeuw verslindt de zebra / De hagedissen zitten op een steen)

(The lion is devouring the zebra / The lizards are sitting on a stone)

14. Lightning striking church

(De kok versiert de taart / The soldaten marcheren)

(The cook is decorating the cake / The soldiers are marching)

15. Girl tickling boy

(De dirigent leidt het orkest / De goudvissen zwemmen in de kom)

(The conductor is conducting the orchestra / The goldfish are swimming in a bowl)

16. Bomb hitting ship

(De kerstman versleept de kerstboom / De schapen grazen)

(Santa Claus is dragging the Christmas tree / The sheep are grazing)

17. Fireman saving boy

(De hond leidt de blinde man / De blinde man en de hond wachten bij de kruising)

(The dog is leading the blind man / The blind man and the dog are waiting at the crossing)

18. Bird pulling worm out of the ground

(De burgemeester onthult het standbeeld / Het stel is aan het rolschaatsen)

(The mayor is unveiling the statue / The couple are rollerskating)

19. Army attacking castle

(Het meisje duwt de jongen op de slee / De cadeautjes liggen onder de kerstboom)

(The girl is pushing the boy on the sled / The presents are under the Christmas tree)

20. Alarm waking up boy

(De wind blaast de papieren weg / De zadels hangen op het hek)

(The wind is blowing the papers away / The saddles are hanging on a fence)

21 . Horse kicking cow

(De bodyguard trekt de president weg / De bewakers staan voor de poort)

(The bodyguard is pulling the president away / Two guards are standing in front of the gate)

22. Policeman arresting man

(De baas stelt de secretaresse voor / De ballonnen knappen)

(The boss is introducing the secretary / The balloons are bursting)

23. Elephant lifting clown

(De piraat begraaft de schat / Het team is aan het praten)

(The pirate is burying the treasure / The team is talking)

24. Ambulance hitting woman

(De padvinder roostert het varken / Het oudere paar houdt elkaars handen vast)

(The boyscout is roasting the pig / The older couple are holding hands)

25. Bishop crowing prince

(De lawine treft de skiers / De sneeuwpoppen smelten)

(The avalanche is hitting the skiers / The snowmen are melting)

26. Helicopter pulling diver out of the water

(De juwelier onderzoekt de diamanten / Het koor zingt)

(The jeweler is examining the diamonds / The choir is singing)

27. Sprinkler splashing old woman

(De gastvrouw laat de man binnen / De fans juichen)

(The hostess is inviting the man in / The fans are cheering)

28. Nurse carrying baby

(De rivier breekt de dam door / De mannen zijn aan het skydiving)

(The river is breaking the dam / The men are skydiving)

29. Cat catching mouse

(De oude ober schopt de man van de trap / Twee mensen lopen onder een paraplu)

(The old waiter is kicking the man down the stairs / Two people are walking under an umbrella)

30. Truck towing car

(De hond likt in het gezicht van de jongen / De dwergen lachen)

(The dog is licking the boy's face / The dwarfs are laughing) 


\section{References}

Altmann, L. J. P., \& Kemper, S. (2006). Effects of age, animacy and activation order on sentence production. Language and Cognitive Processes, 21, 322-354.

Baayen, R. H., Davidson, D. J., \& Bates, D. M. (2008). Mixed-effects modeling with crossed random effects for subjects and items. Journal of Memory and Language, 59, 390-412.

Barr, D. J. (2008). Analyzing ‘visual world’ eyetracking data using multilevel logistic regression. Journal of Memory and Language, 59, 457-474.

Barr, D. J., Levy, R., Scheepers, C., \& Tily, H. J. (2013). Random effects structure for confirmatory hypothesis testing: Keep it maximal. Journal of Memory and Language, 68, 255-278.

Bates, E., \& MacWhinney, B. (1982). Functionalist approaches to grammar. In E. Wanner \& L. R. Gleitman (Eds.), Language acquisition: The state of the art (pp. 173-218). Cambridge: Cambridge University Press.

Bock, J. K. (1982). Toward a cognitive psychology of syntax: Information processing contributions to sentence formulation. Psychological Review, 89, 1-47.

Bock, J. K. (1986a). Syntactic persistence in language production. Cognitive Psychology, 18, 355-387.

Bock, J. K. (1986b). Meaning, sound, and syntax: Lexical priming in sentence production. Journal of Experimental Psychology: Learning, Memory, and Cognition, 12, 575-586.

Bock, J. K. (1987a). Coordinating words and syntax in speech plans. In A. Ellis (Ed.). Progress in the psychology of language (Vol. 3). London: Erlbaum.

Bock, J. K. (1987b). An effect of the accessibility of word forms on sentence structures. Journal of Memory and Language, 26, 119-137.

Bock, J. K., \& Griffin, Z. M. (2000). The persistence of structural priming: Transient activation or implicit learning? Journal of Experimental Psychology: General, 129, 177-192.

Bock, J. K., \& Irwin, D. (1980). Syntactic effects of information availability in sentence production. Journal of Verbal Learning and Verbal Behavior, 19, 467-484.

Bock, J. K., Irwin, D. E., \& Davidson, D. J. J. (2004). Putting first things first. In F. Ferreira \& M. Henderson (Eds.), The integration of language, vision, and action: Eye movements and the visual world (pp. 249-278). New York: Psychology Press.

Bock, J. K., Irwin, D. E., Davidson, D. J., \& Levelt, W. J. M. (2003). Minding the clock. Journal of Memory and Language, 48, 653-685.

Bock, J. K., Loebell, H., \& Morey, R. (1992). From conceptual roles to structural relations: Bridging the syntactic cleft. Psychological Review, 99, 150-171.

Bock, J. K., \& Warren, R. K. (1985). Conceptual accessibility and syntactic structure in sentence formulation. Cognition, 21, 47-67.

Branigan, H. P., Pickering, M. J., \& Tanaka, M. (2008). Contributions of animacy to grammatical function assignment and word order during production. Lingua, 118, 172-189.

Brown-Schmidt, S., \& Konopka, A. E. (2008). Little houses and casas pequeñas: Message formulation and syntactic form in unscripted speech with speakers of English and Spanish. Cognition, 109, 274-280.

Brown-Schmidt, S., \& Konopka, A. E. (2011). Experimental approaches to referential domains and the on-line processing of referring expressions in unscripted conversation. Information, 2, 302-326.

Brown-Schmidt, S., \& Tanenhaus, M. K. (2006). Watching the eyes when talking about size: An investigation of message formulation and utterance planning. Journal of Memory and Language, 54, 592-609.

Bunger, A., Papafragou, A., \& Trueswell, J. (2013). Event structure influences language production: Evidence from structural priming in motion event description. Journal of Memory and Language, 69(299), 323.

Chang, F., Bock, K., \& Goldberg, A. (2003). Can thematic roles leaves traces of their places? Cognition, 90, 29-49.

Chang, F., Dell, G. S., \& Bock, K. (2006). Becoming syntactic. Psychological Review, 113, 234-272.

Christianson, K., \& Ferreira, F. (2005). Conceptual accessibility and sentence production in a free word order language (Odawa). Cognition, 98, 105-135.

Dobel, C., Gumnior, H., Bolte, J., \& Zwitserlood, P. (2007). Describing scenes hardly seen. Acta Psychologica, 125, 129-143.

Ferreira, F. (1994). Choice of passive voice is affected by verb type and animacy. Journal of Memory and Language, 33(6), 715-736.

Ferreira, V. S. (1996). Is it better to give than to donate? Syntactic flexibility in language production. Journal of Memory and Language, 35, 724-755.

Ferreira, V. S., \& Bock, K. (2006). The functions of structural priming. Language and Cognitive Processes, 21, 1011-1029.

Ferreira, F., \& Henderson, J. M. (1998). Linearization strategies during language production. Memory and Cognition, $26,88-96$.

Ferreira, F., \& Swets, B. (2002). How incremental is language production? Evidence from the production of utterances requiring the computation of arithmetic sums. Journal of Memory and Language, 46, 57-84.

Fisher, C. (2002). The role of abstract syntactic knowledge in language acquisition: A reply to Tomasello (2000). Cognition, 82, 259-278.

Fisher, C., Gleitman, H., \& Gleitman, L. R. (1991). On the semantic content of subcategorization frames. Cognitive Psychology, 23, 331-392.

Gleitman, L., January, D., Nappa, R., \& Trueswell, J. C. (2007). On the give and take between event apprehension and utterance formulation. Journal of Memory and Language, 57, 544-569.

Griffin, Z. M., \& Bock, K. (2000). What the eyes say about speaking. Psychological Science, 11, 274-279.

Griffin, Z. M. (2004). Why look? Reasons for speech-related eye movements. In F. Ferreira \& M. Henderson (Eds.), The integration of language, vision, and action: Eye movements and the visual world (pp. 191-211). New York: Psychology Press.

Hafri, A., Papafragou, A., \& Trueswell, J. C. (2012). Getting the gist of events: Recognition of two-participant actions from brief displays. Journal of Experimental Psychology: General. http://dx.doi.org/10.1037/a0030045.

Hartsuiker, R. J., Bernolet, S., Schoonbaert, S., Speybroeck, S., \& Vanderelst, D. (2008). Syntactic priming persists while the lexical boost decays: Evidence from written and spoken dialogue. Journal of Memory and Language, 58, 214-238.

Henderson, J. M., \& Ferreira, F. (2004). Scene perception for psycholinguistics. In F. Ferreira \& M. Henderson (Eds.), The integration of language, vision, and action: Eye movements and the visual world (pp. 1-58). New York: Psychology Press.

Henderson, J. M., Malcolm, G. L., \& Schandl, C. (2009). Searching in the dark: Cognitive relevance drives attention in real-world scenes. Psychonomic Bulletin and Review, 16, 850-856. 
Jaeger, T. F. (2008). Categorical data analysis: Away from ANOVAs (transformation or not) and towards logit mixed models. Journal of Memory and Language, 59, 434-446.

Kempen, G., \& Hoenkamp, E. (1987). An incremental procedural grammar of sentence formulation. Cognitive Science, 11, 201-258.

Konopka, A. E. (2012). Planning ahead: How recent experience with structures and words changes the scope of linguistic planning. Journal of Memory and Language, 66, 143-162.

Kuchinsky, S. E. (2009). From seeing to saying: Perceiving, planning, producing. Unpublished doctoral dissertation, University of Illinois at Urbana-Champaign.

Kuchinsky, S. E., \& Bock, K. (2010). From seeing to saying: Perceiving, planning, producing. Paper presented at the 23rd meeting of the CUNY human sentence processing conference, New York, NY.

Kuchinsky, S. E., Bock, K., \& Irwin, D. E. (2011). Reversing the hands of time: Changing the mapping from seeing to saying. Journal of Experimental Psychology: Learning, Memory, and Cognition, 37, 748-756.

Levelt, W. J. M. (1989). Speaking: From intention to articulation. Cambridge, MA: MIT Press.

McDonald, J. L., Bock, K., \& Kelly, M. H. (1993). Word and world order: Semantic, phonological, and metrical determinants of serial position. Cognitive Psychology, 25, 188-230.

Meyer, A. S., \& Lethaus, F. (2004). The use of eye tracking in studies of sentence generation. In F. Ferreira \& M. Henderson (Eds.), The integration of language, vision, and action: Eye movements and the visual world (pp. 191-211). New York: Psychology Press.

Myachykov, A., Garrod, S., \& Scheepers, C. (2009). Attention and syntax in sentence production: A critical review. Discours, 4(special issue: Linearization and Segmentation in Discourse). http://dx.doi.org/10.4000/discours.7594.

Myachykov, A., Garrod, S., \& Scheepers, C. (2012). Determinants of structure choice in visually situated sentence production. Acta Psychologica, 141, 304-315.

Norcliffe, E., Konopka, A. E., Brown, P., \& Levinson, S. (2013). Word order affects the timecourse of sentence formulation in Tzeltal. Paper presented at the 26th meeting of the CUNY human sentence processing conference, Columbia, SC, USA.

Osgood, C. E., \& Bock, J. K. (1977). Salience and sentencing: Some production principles. In S. Rosenberg (Ed.), Sentence production: Developments in research and theory (pp. 89-140). Hillsdale, NJ: Erlbaum.

Pickering, M. J., \& Branigan, H. P. (1998). The representation of verbs: Evidence from syntactic priming in language production. Journal of Memory and Language, 39, 633-651.

Pickering, M. J., \& Ferreira, V. S. (2008). Structural priming: A critical review. Psychological Bulletin, 134, 427-459.

Potter, M. C. (1976). Short-term conceptual memory for pictures. Journal of Experimental Psychology: Human Learning and Memory, 2, 509-522.

Prat-Sala, M., \& Branigan, H. P. (2000). Discourse constraints on syntactic processing in language production: A cross-linguistic study in English and Spanish. Journal of Memory and Language, 42, 168-182.

Sauppe, S., Norcliffe, E., Konopka, A. E., van Valin, R. D., \& Levinson, S. (2013). Dependencies first: Eye-tracking evidence from sentence production in Tagalog. Paper to be presented at the 35th meeting of the Cognitive Science Society, Berlin, Germany.

Smith, M., \& Wheeldon, L. (2001). Syntactic priming in spoken sentence production - An online study. Cognition, 78, 123-164.

Tomasello, M. (2000). Do young children have adult syntactic competence? Cognition, 74, 209-253.

Tomlin, R. (1995). Focal attention, voice, and word order: An experimental, cross-linguistic study. In M. Noonan \& P. Downing (Eds.), Word order in discourse (pp. 521-558). Amsterdam: John Benjamins.

Tomlin, R. (1997). Mapping conceptual representations into linguistic representations: The role of attention in grammar. In J. Nuyts \& E. Pederson (Eds.), Language and conceptualization (pp. 162-189). Cambridge: Cambridge University Press.

Van de Velde, M., Meyer, A. S., \& Konopka, A. E. (2014). Message formulation and structural assembly: Describing "easy" and "hard" events with preferred and dispreferred syntactic structures. Journal of Memory and Language, 71, $124-144$.

Wagner, V., Jescheniak, J. D., \& Schriefers, H. (2010). On the flexibility of grammatical advance planning during sentence production: Effects of cognitive load on multiple lexical access. Journal of Experimental Psychology: Learning, Memory, and Cognition, 36, 423-440.

Wheeldon, L. (2013). Producing spoken sentences: The scope of incremental planning. In P. Perrier and P. Lang Verlag (Eds.), Cognitive and physical models of speech production, speech perception, and production-perception integration. 